Louisiana State University

LSU Digital Commons

1963

\title{
Surveying the Man-In-The-Middle of an Industrial Organization.
}

James Agnew Vaughan Jr

Louisiana State University and Agricultural \& Mechanical College

Follow this and additional works at: https://digitalcommons.Isu.edu/gradschool_disstheses

\section{Recommended Citation}

Vaughan, James Agnew Jr, "Surveying the Man-In-The-Middle of an Industrial Organization." (1963). LSU Historical Dissertations and Theses. 904.

https://digitalcommons.Isu.edu/gradschool_disstheses/904

This Dissertation is brought to you for free and open access by the Graduate School at LSU Digital Commons. It has been accepted for inclusion in LSU Historical Dissertations and Theses by an authorized administrator of LSU Digital Commons. For more information, please contact gradetd@lsu.edu. 
This dissertation has been 64-5064 microfilmed exactly as received

VAUGHAN, Jr., James Agnew, 1936SURVEYING THE MAN-IN-THE-MIIDDLE OF AN INDUSTRIAL ORGANIZATION.

Louisiana State University, Ph.D., 1963

Psychology, general

University Microfilms, Inc., Ann Arbor, Michigan 
SURVEYING THE MAN-IN-THE-MIDDLE

OF AN INDUSTRIAL ORGANIZATION

\section{A Dissertation}

Submitted to the Graduate Faculty of the Louisiana State University and Agricultural and Mechanical college in partial fulfillment of the requirements for the degree of Doctor of Philosophy

in

The Department of Psychology

by James Agnew Vaughan, $\mathrm{Jr}$. B.A., Milisaps College, 1958 M.A., Wesleyan University, 1960 August, 1963 


\section{ACKNOWLEDGMENT}

The author wishes to express his appreciation to the following persons who helped bring this research project to completion:

To Dr. Roland L. Frye and Dr. Bernard M. Bass for their guidance and constructive criticisms of the manuscript.

To the other members of the author's committee, Dr. Fredertck L. Bates, Dr. Joe1 R. Butler, Dr. Donald R. Hoffeld, Dr. Lee M. Taylor, and Dr. Robert N. Vidulich, for their consideration and guidance in the early stages.

To Robert Voytas and Edward Teitlebaum for their assistance in data analysis and to Mrs. Audrey Silver and the author's wife for typing the manuscript. 
PAGE

TITE PAGE

ACKNOWLEDGMENT

LIST OF TABLES

ABSTRACT

INTRODUCTION

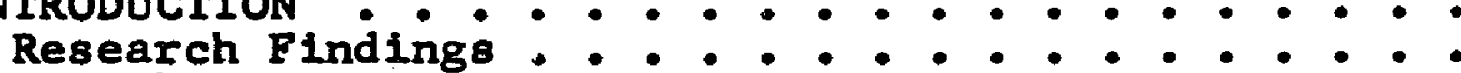

Hypotheses

PROCEDURE

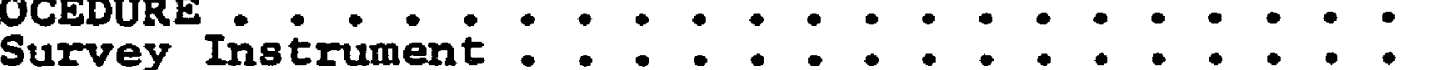

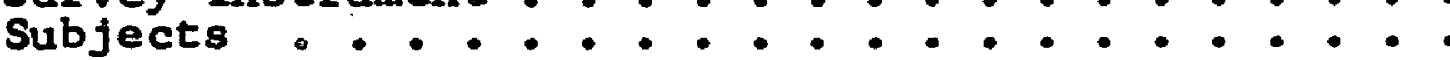

vi1

Scoring.

RESULTS

Item Responses

Factor Patterns

Analyses of Variance

DISCUSSION

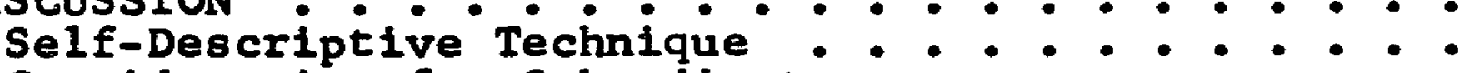

Consideration for Subordinates . . . . . . . . . .

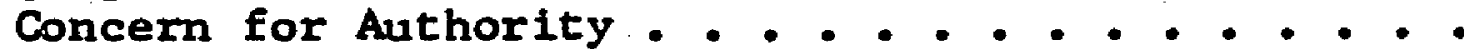

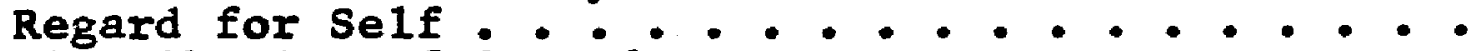

Distribution of Reward

General Organizational Concern

Time With the Organization and Distribution of

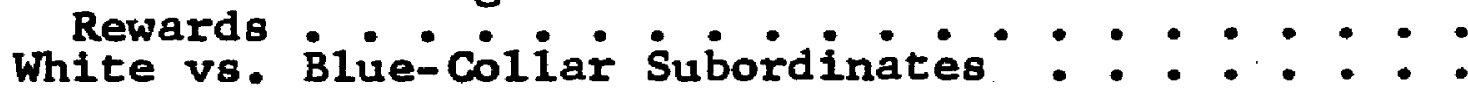

Concern for Authority and the Linking Pin

Function

Initiation

Conf1ict

Estimation

Levels in the Organization

Departmenta1 Differences

Implications for Future Research 
TABLE OF CONTENTS (cont.)

PAGE

SUMMARY AND CONCLUSION . . . . . . . . . . 55

REFERENCES ...................... 57

APPENDICES ........................ 60

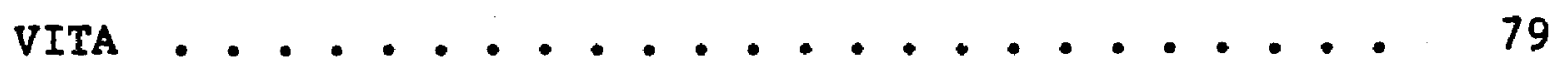




\section{LIST OF TABLES}

TABLE

PAGE

I Design of 48 Questions Relating to Reference Group and Problem Areas . . . . . . . .

II Means and Standard Deviations for Items 1 to 48 ....................

II Frequencies of Alternatives Chosen on Items 1 to vili and 49 to 58 ............ 14

IV Means, Standard Deviations, and Reliability Coefficients of the Fourteen Subscales . .

V Unrotated Factor Structure . . . . . . . 17

VI Rotated Factor Structure . . . . . . . . 18

VII Partial Summary of Means and $F$ Values for Analyses of Varlance of Time as Head of Department

VIII Partial Summary of Means and F Values for Analyses of Variance of Time in Organization

IX Partial Summary of Means and $F$ Values for Analyses of Variance of Type of Subordinate . . . . . . . . . . . . . .

$X$ Partial Summary of Means and $F$ Values for Analyses of Variance of Skill Level of Department . . . . . . . . . . . . . .

XI Partial Summary of Means and $F$ Values for Analyses of Variance of Responses to Disagreement with Boss about Intraorganizational Decisions . . . . . . .......

XII Partial Summary of Means and F Values for Analyses of Variance of Responses to Disagreement with Peers about Participation 


\section{LIST OF TABLES (cont.)}

TABLE

PAGE

XII Partial Sumiary of Means and F Values for Analyses of Variance of Reactions to Rulebook Interfering with Departmental

Activities ............... . . . .

XIV Partial Summary of Means and $F$ Values for Analyses of Variance of Reactions to Outsiders Attempting to Influence Planning . . .

XV Partial Summary of Means and $F$ Values for Analyses of Variance of Reactions to Boss-Subordinate Confilct . . . . . . . . . . .

XVI Partial Summary of Means and $\mathbf{F}$ Values for Analyses of Vartance of Descriptions of Boss Behavior in Conflict

XVII Partial Summary of Means and $F$ Values for Analyses of Varlance of Satisfaction of Subordinates. . . . . . . . . . . . . . .

XVIII Partial Summary of Means and $F$ Values for Analyses of Variance of Levels in Organization

XIX Partial Summary of Means and $F$ Values for Analyses of Variance of Departments in the Organization 


\section{ABSTRACT}

The man-in-the-middle in industrial organizations faces a unique set of problems by virtue of the fact that he has dual responsibilities. He must answer to his superiors, on the one hand, and his subordinates, on the other. Rapid technological developments in production and information systems, along with certaln culturally based changes in expectations of workers and supervisors, have intensified these problems.

The purpose of this study was to search for patterns in the way in which the men-in-the-middle of a given organization describe with whom they consult about a number of different organizational problems.

The Ss for the study were 109 supervisors from a large industrial organization involved in the manufacture of liquid rockets. The Ss represent a subsample from three levels of supervision from five departments: Research and Development, Engineering, Engineering Services, Administrative Services and Operations. They are somewhat unique because of their relatively high level of education and the specialized nature of their training. .

The method employed in this investigation was a written survey. The survey instrument was the Pittsburgh Administrative Review (PAR), a self-descriptive, multiple-choice questionnaire designed specifically for this type study. PAR yields 14 
subscale scores, six of which indicate the degree of attention paid certain problem areas and elght of which indicate the degree of consulting reported with certain loct of concern in the organization. PAR also contains some objective questions concerning the nature of the individual's position in the organization.

Scoring of the questionnaire was accomplished on the IBM 7070 computer. The resulting subscale scores were submitted to a series of analyses of variance, grouped on the basis of the Ss' responses to specific questions on PAR and other objective organizational data. A principle axis factor analysis was utilized to provide an additional set of factor scores, which were also submitted to analyses of variance as described above.

Five well-defined factors emerged from the analysis. Factor I was named Consideration for Subordinates. It appears to represent the same dimension as the consideration factor isolated in the Ohio State Leadership Studies. A high score on Consideration for Subordinates was most often accompanied by a low score on Factor II, Concern for Authority. The latter factor represents a tendency to consult with one's boss and formal organizational policy when making decisions.

Factor III, Regard for Self, reflects a high degree of self-concern and rejection of others in decision-making. Factor IV, Distribution of Reward, measures a high degree of concern with schedules of remuneration.

Factor V, General Organizational Concern, represents what is perhaps the most rational approach to the problems faced 
by the man-in-the-middle. The pattern is one of consulting with relevant persons about relevant problems.

Consistent differences were found between the reported consulting patterns of Ss with white-collar and Ss with bluecollar subordinates. The former group consulted more with subordinates while the latter paid more attention to the boss and rulebook.

Several of the analyses of variance yielded significant differences in Concern for Authority. Those Ss who showed an extremely low regard for authority also evidenced a general lack of concern about other organizational matters.

A consistent trend was found with supervisory level in the organization and Concern for Authority. Those in the higher levels reported the least amount of consulting with boss and rulebook, while those in the lower levels reported the most.

Subjects in Engineering departments showed a higher degree of consideration for subordinates than any of the Ss in other departments. This is seen as evidence of a new breed of technical supervisors. 


\section{INTRODUCTION}

Mach has been written in recent years about the nature of organizations in general, and more specifically, about the nature of channels of communications, hierarchies of authority and the rapidly changing patterns of management and supervision. Many writers have begun to focus attention on the perennial man-in-the-middle, i.e., the person in the organization who is continually subjected to pressure from above in the form of his superiors' expectations and explicit orders concerning output, and from below in the form of his subordinates' expectattons that he look out for their welfare (Blau \& Scott, 1962; Dubin, 1961; Tannenbaum, et a1., 1961; Bass, 1960; Leavitt, 1958; Roeth1isberger, 1945). The significance of the man-inthe-middle phenomenon is brought home by the fact that virtually everyone, at one time or another, finds himself in this situation, whether it be in industry, a social club, church, one's family, etc.

The problems of the man-in-the-middle in industry have become intensified with many recent developments in culture and technology. Argyris (1957) emphasizes the dilemma in which management finds itself in attempting to adhere to traditional management principles and at the same time to allow for the fulfillment of the mature personalities which our culture is striving to produce. The increasing level of education of workers today is closely associated with a sharp rise in the 
amount of responsibility, authority and income they expect to receive and a sharp drop in the amount of pressure and close supervision they are willing to accept.

Likert (1961) points to the need for greater cooperation and participation at all levels of management. With the increase in research and development, the rapid growth of new fields of engineering, the increased use of more complex forms of mathematics and statistics and the introduction of large computers, the transmission and retention of information needed to solve complex problems presents a serious problem and challenge to management. Many decisions require the knowledge and know-how of many experts from different fields so that the "chief" can no longer make individual decisions based on the "best facts" available. In fact, it is fairly commonplace for the subordinates to command more of the relevant facts in the situation than their superiors.

When one begins to study the men-in-the-middle in a given organization, he very soon appreciates the statement that "flow charts tell one kind of story and the behavior of people another story, often a contradictory one" (Gilmer, 1961).

\section{Research Findings}

This study is a self-descriptive survey of the man-in-themiddle in a large industrial organization, the main purpose of which is to seek out patterns in these self-descriptions of behavior. A number of general patterns of behavior by men-inthe-middle have been reported (Bass \& Vaughan, 1962):

1. Some identify completely with superiors and organizational 
derands, disparaging any concern for subordinates. They reduce Intimacy with subordinates to avoid any sense of guilt over lack of consideration for them or compromise by being friendly, but only "off the job" (Hites, 1953).

2. Some identify completely with subordinates, probably leading to fallure to carry out responsibilities to their organIzation (Hites, 1953).

3. Some successfully initiate structure for their subordinates as demanded by their organization, at the same time maintaining considerate, friendly awareness of the needs of their subordinates (Roff, 1950).

4. Some acquiesce to their superiors and rationalize their position to their subordinates (Roff, 1950).

5. Some are hypocritical, insincere, practicing duplicity in order to avoid disapproval from above or below, 1. e., they tell the boss about how lazy their subordinates are and tell their subordinates what a slave driver the boss is (Titus, 1950).

6. Some develop blind spots in their environment so that they refuse to accept the existence of confilct (Dalton, 1960).

7. Some deal with superior-subordinate confliets by a form of withdrawal, wearing a "mask," seemingly neutral and objective (Pfiffner, 1951).

8. Some employ other of the various defense mechanisms to cope with the superior-subordinate conflict such as: displaced aggression--"some outside agitators are inciting my subordinates to rebel or confusing my boss about what my subordinates are really like"; introjection--"the failure of my subordinates is my fault; I'11 take the blame." 
Barnes (1960) discusses some of the unique problems of the engineering supervisor as the man-in-the-middle. He is forced to play two roles which are the source of much conflict. To management he plays the role of the engineer, stressing scientific principles, quality and developmental work; and to the engineers beneath him, he displays a dominant concern for productivity and practicality.

The present study was designed to go a step beyond the previously cited works and identify specific patterns of behavior, namely, with whom the man-in-the-middle consults when faced with certain types of problems within the organization.

It is we11 documented that superiors and subordinates quite often have different and conflicting expectations of the manIn-the-middle (Brooks, 1955; Stouffer, 1957; Bass, 1960; Roethlisberger, 1956; Halpin, 1957). Jambor (1954) reports that the intensity of role conflict differs as a function of the status level from which it derives. The supervisor who occupies the middle status position experiences more conflict and anxiety when his superiors" expectations conflict with his own than when his own conflict with his subordinates' expectations. While the present study is not directed specifically at a comparison of role expectations, it is hoped that some insights will be gained concerning the expectations of the manin-the-middle. To date, most of the work in this area has been concerned with what others in the organization expect of the man-in-the-middle; this study will reverse the procedure and focus on what the man-in-the-middle expects of others. 
Hypotheses

The following are some specific hypotheses which the author proposed to investigate:

1. The tendency to consult with subordinates varies inversely with the sheer size of department while the tendency to consult with the boss varies directly with same. As the number of subordinates increases, the problems of communication downward are intensifted, while the communication channels upward become more accessible, and in fact, demand more frequent communication because of increased responsibility.

2. The tendency to consult with subordinates will be greater in departments that are essentially semi-professional or skilled rather than semi-skilled or unskilled. The former group possesses more relevant information necessary in the operation of given departments.

3. The tendency to consult with one's boss will correlate positively with tendency to consult with peers but negatively with tendency to consult with subordinates.

4. Those who report a relatively high degree of consultation with their subordinates will also report their subordinates to be more satisfied with their jobs.

5. Those who feel that their boss is coercive will consult more with peers and persons above them in the organization other than their boss. 
PROCEDURE

\section{Survey Instrument}

The survey instrument employed in this study was a multiplechoice questionnaire, the Pittsburgh Administrative Review (PAR), a copy of which may be seen in Appendix A. PAR is self-administering and can be broken down into three distinct sections.

Section 1. The first section (items 1-viii) is informational in character and is intended to provide some objective data about the individual's relationship to his organization.

Section 2. The second section (items 1-48) is designed to obtain fourteen subscale scores as follows: Each item refers to one of elght possible loci of concern and one of six possible problem areas, and all possible combinations between the various loci of concern and problem areas are included. Table I shows the design.

It can be seen from Table I that elght subscale scores (based on six items each) will indicate with whom the individual consults or whom he "considers," irregardless of problem area; and six subscale scores (based on eight ltems each) will indicate his judgment of the relative importance of the problem areas over all loct of concern. The eight loci of concern seem to be all inclusive, whereas the six problem areas are simply six among many which seem to be of significance in industrial organizations. Four of the six are major headings in March \& Simon's (1958) Organizations. 
TABLE I

Design of 48 Questions Relating to

Reference Group and Problem Areas

\begin{tabular}{|c|c|c|c|c|c|c|}
\hline & $\begin{array}{l}1 . \\
\text { Intraorgan- } \\
\text { izational } \\
\text { Decisions }\end{array}$ & $\begin{array}{l}2 . \\
\text { Partici- } \\
\text { pation }\end{array}$ & ${ }_{\text {Confilet }}^{\text {Pro }}$ & $\begin{array}{l}\text { blem Area } \\
\text { Coordination } \\
\text { and Mainte- } \\
\text { nance of Dept. } \\
\text { Program }\end{array}$ & $\begin{array}{l}5 . \\
\text { Planning } \\
\text { and Inno- } \\
\text { vation }\end{array}$ & $\begin{array}{l}6 . \\
\text { Distribu- } \\
\text { tion of } \\
\text { Rewards }\end{array}$ \\
\hline 7. Boss & 19 & 34 & 39 & 11 & 1 & 28 \\
\hline 8. Peers & 33 & 20 & 16 & 4 & 29 & 40 \\
\hline 9. Subordinates & 36 & 12 & 3 & 30 & 42 & 44 \\
\hline of 10. Rulebook & 15 & 2 & 27 & 21 & 45 & 10 \\
\hline 예 11. Outsiders & .5 & 26 & 41 & 46 & 7 & 17 \\
\hline w 12. Self & 25 & 24 & 47 & 8 & 14 & 22 \\
\hline $\begin{array}{l}\text { 13. Persons above } \\
\text { me in the or- } \\
\text { gantzation } \\
\text { other than my } \\
\text { boss }\end{array}$ & 38 & 6 & 13 & 23 & 35 & 31 \\
\hline $\begin{array}{l}\text { 14. Persons below } \\
\text { me in the or- } \\
\text { ganization in } \\
\text { other depart- } \\
\text { ments }\end{array}$ & 48 & 43 & 9 & 18 & 32 & 37 \\
\hline
\end{tabular}


Half of the items in this section were cast negatively so that a choice of the alternative "always" actually indicates "never" In reference to the particular content. This was done to counteract a possible acquiescence effect, a general tendency to agree with ttems, regardless of their content.

Section 3. The third section (items 49-58) contains elght questions concerning the six problem areas and two questions concerning the relative satisfaction of the individual's subordinates and the effectiveness of his department. The first efght questions of this section differ from the previous 48 in that the alternatives are specific behe tors rather than frequency responses, and some contain two reference groups rather than one.

As one sees in the Introduction to PAR in Appendix A, PAR was adminiatered to the Ss three different times, calling for three different responses. This study, however, only considered the first set of responses, namely, the Ss' descriptions of their actual behavior. Each $S$ completed the questionnaire individually with no time 1imit, and all data was collected within a three week period.

Subjects

The subjects for the study were 109 supervisors and managers from a large industrial organization on the West coast of the United States. Subsamples from 12 different departments are represented in the total sample as follows:

Function of Department №. of Depts. №. of Supervisors

Research \& Development 
Function of Department №. of Depts. No. of Supervisors

Englneering

Engineering Services

Fabrication

Quality Control

Administrative Services

Procurement

Technical Services

Contracts

3

28

1

1

19

1

Operations

Manufacturing

Test Area
1
9

9

9

9

9

Three levels of management are represented as follows:

1. Upper Managers (14)

2. Midd1e Managers (46)

3. Lower Managers and Supervisors (49)

In terms of trainting and expertence, these Ss are probably typical of the type which one would find in any large industry involved in the design and manufacture of rockets and rocketrelated components. At the same time, they are, no doubt, quite different from the personnel one would expect to find in a more traditional industry involved, for example, in the marufacture of some common consumable product. The Ss in the present study contain many more people trained in diverse, complex technologies and highly specialized skills and professions, almost all of whom are college graduates.

\section{Scoring}

Scoring the questionnaire was accomplished by means of an IBM 7070 Item Analysis Program (Bendig, 1962a). Numerical weights were assigned to the alphabetic alternatives on the 
questionnaire as follows: For all positive questions, $A=5$, $B=4, C=3, D=2$ and $E=1$; for all negative questions, $A=1, B=2, C=3, D=4$ and $E=5$. Therefore, the higher the numeric score on a given item, the greater the degree of consulting or concern the subject is indicating. Means and standard deviations of items 1 to 48 were computed on this basis.

The mean and standard deviation are not appropriate descriptive statistics for items 1 to vili and 49 to 58 because of the discontinuous nature of the alternatives. The frequences of the alternatives chosen for these items are shown instead.

Scores on each of the 14 subscales were computed for each $S$ by summing the weights of the items assigned to a given subscale. For example, a score on the Boss subscale was obtained by summing the weighted responses to items $1,11,19,28,34$ and 39. Again, a high numeric score on a given subscale indicates a greater degree of consulting or concern. A reliability estimate of each subscale was obtained, using the Kuder-Richardson Formula 20 (Downie, 1958).

Factor Analysis. A second method of scoring was derived from a factor analysis of items 1 to 48 . The intercorrelation matrix for the items was obtained using the Pearson Product Moment Correlation Formula. A principle axis factor analysis (Bendig, 1962b) was performed on the matrix and the resulting factors were submitted to a varimax rotation (Bendig, 1961). From this rotated structure, five factors were chosen to be used in scoring.

Factor Scores. There are several ways to obtain factor scores, the guiding principle being to combine the items which 
load highest on a given factor in a manner that best predicts the factor. Cattell (1952) points out that although a number of sophisticated weighting techniques utilizing multiple regression are avaliable, the gain over simply suming the raw scores Is not usually appreciable, especially in cases where the factor loadings of the items are not very different. Since the latter was true of this data, the simple method of summing the raw scores was chosen for scoring. In cases where there were high positive and negative loadings on the same factor, the negative item scores were subtracted from the positive ones. Analyses of Variance. Both sets of scores described above were then evaluated by a series of simpie analyses of variance. The first series utilized the responses to the items in sections one and three of PAR to break the Ss into groups. For example, the frequencies of responses to item 1 concerning department size were as follows:

Size of Department
A. 5 or 1 ess
B. $6-10$
C. $11-20$
D. $21-30$
E. over 30 persons

Frequency

24

20

22

11

30

(Any subject who did not respond to the item in question was not included in the analysis of that item.) These then formed the groups for 19 separate analyses of variance, 14 on the subscale scores and 5 on the factor scores. Questions vili, 52 and 54 were not utilized in this fashion because the distribution of alternatives chosen was not sufficient to warrant breaking the data into groups.

Additional analyses of variance were performed among the departments and the levels in the organization. 


\section{RESULTS}

\section{Item Responses}

Table II shows the mean responses and the standard deviations for items 1 to 48. (For purposes of interpretation, 1 = never, ..., 5 = always.) Table III displays the frequencies of the alternatives chosen for items $i$ to vili and 49 to 58 .

Table IV shows the means, standard deviations and rellability coefficients of the subscales. An inspection of this table reveals that even though the first $81 x$ subscales referring to problem areas were composed of more items, their rellability estimates were considerably lower than all of the locus of concern subscales with the exception of the self scale. This would seem to indicate that the problem under consideration yields less consistency than person with whom one is consulting. The Ss were more consistently different in attending to specific others or themselves regardless of the problem.

The usefulness of individual problem area subscale scores then is quite questionable because of their low estimated reliability. However, these scores were included in the analyses of variance, and they did yield soine consistent differences which will be discussed later. While the reliability estimates of the loci of concern are not astounding, they are gratifyingly high, considering the small number of items on which they are based. Also, they are conservative, for individual differences 


\section{TABLE II}

Means and Standard Deviations

For Items 1 to 48

\section{Item}

1. Boss - Plan. and Innov.

2. Rulebook - Participation

3. Subordinate - Conflict

4. Peers - Coord. \& Maint.

5. Outsiders - Intraorgan. Dec.

6. Persons above - Participation

7. Outsiders - Plan. and Innov.

8. Self - Coord. \& Maint.

9. Persons below - Conflict

10. Rulebook - Dist. of Rew.

11. Boss - Coord. \& Maint.

12. Subord Inates - Participation

13. Persons above - Conflict

14. Self - Plan. and Innov.

15. Rulebook - Intraorgan. Dec.

16. Peers - Conflict

17. Outsiders - Dist. of Rew.

18. Persons below - Coord. \& Malnt.

19. Boss - Intraorgan. Dec.

20. Peere - Participation

21. Rulebook - Coord. \& Maint.

22. Self - Dist. of Rew.

23. Persons above - Coord. \& Maint.

24. Self - Participation

25. Self - Intraorgan. Dec.

26. Outsiders - Particlpation

27. Rulebook - Conflict

28. Boss - Dist. of Rew.

29. Peers - Plan. and Innov.

30. Subordinates - Coord. \& Maint.

31. Persons above - Dist. of Rew.

32. Persons below - Plan. and Innov.

33. Peers - Intraorgan. Dec.

34. Bos8 - Particlpation

35. Persons above - Plan. and Innov.

36. Subordinates - Intraorgan. Dec.

37. Persons below - Dist. Of Rew.

38. Persons above - Intraorgan. Dec.

39. Boss - Confilct

40. Peers - D1st. of Rew.

41. Outsiders - Conflict

42. Subord inates - Plan. and Innov.

43. Persons below - Participation

44. Subordinates - Dist. of Rew.

45. Rulebook - Plan. and Innov.

46. Outsiders - Coord. \& Maint.

47. Self - Conflict

48. Persons below - Intraorgan. Dec.

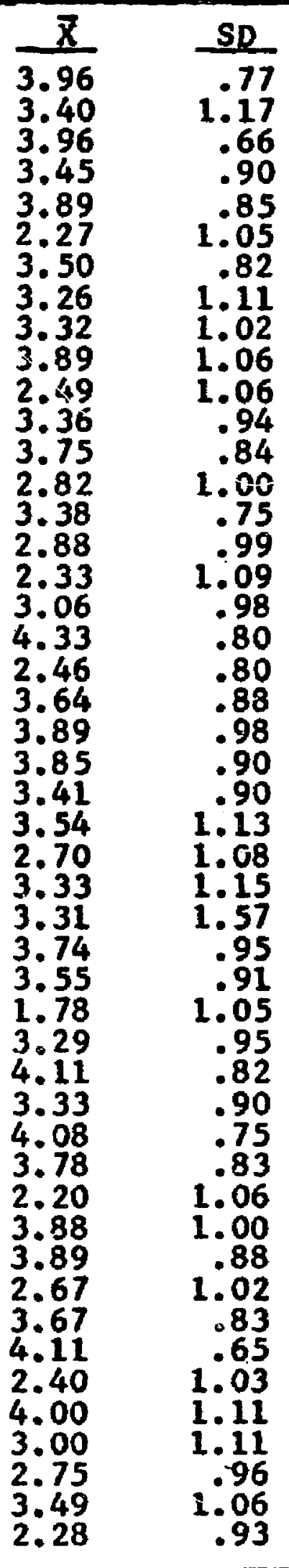


TABLE III

Frequencles of Alternatives Chosen on Items 1 to vi11 and 49 to 58

\begin{tabular}{rrrrrrr}
\hline Item & A & B & C & D & E & $Q^{*}$ \\
II & 24 & 20 & 22 & 11 & 30 & 2 \\
i1 & 48 & 20 & 24 & 13 & 0 & 4 \\
iv & 9 & 22 & 24 & 47 & 5 & 2 \\
v & 42 & 16 & 30 & 45 & 9 & 1 \\
vi & 44 & 31 & 17 & 4 & - & 25 \\
vi1 & 34 & 66 & 2 & 5 & 6 & 16 \\
vi11 & 63 & 1 & 0 & 1 & - & 7 \\
49 & 0 & 8 & 27 & 74 & 0 & 44 \\
50 & 1 & 4 & 26 & 67 & 5 & 6 \\
51 & 9 & 35 & 50 & 1 & 3 & 11 \\
52 & 0 & 4 & 5 & 96 & 0 & 4 \\
53 & 17 & 2 & 73 & 9 & 3 & 5 \\
54 & 72 & 3 & 1 & 2 & 11 & 20 \\
55 & 24 & 7 & 6 & 3 & 58 & 11 \\
56 & 8 & 23 & 66 & 2 & 6 & 4 \\
57 & 23 & 63 & 9 & 6 & 0 & 8 \\
58 & 31 & 62 & 12 & 1 & 1 & 2 \\
\hline
\end{tabular}

* Indicates item was judged by subject as not applicable to himself. 
TABLE IV

Means, Standard Deviations, and Reliability Coefficients of the Fourteen Subscales

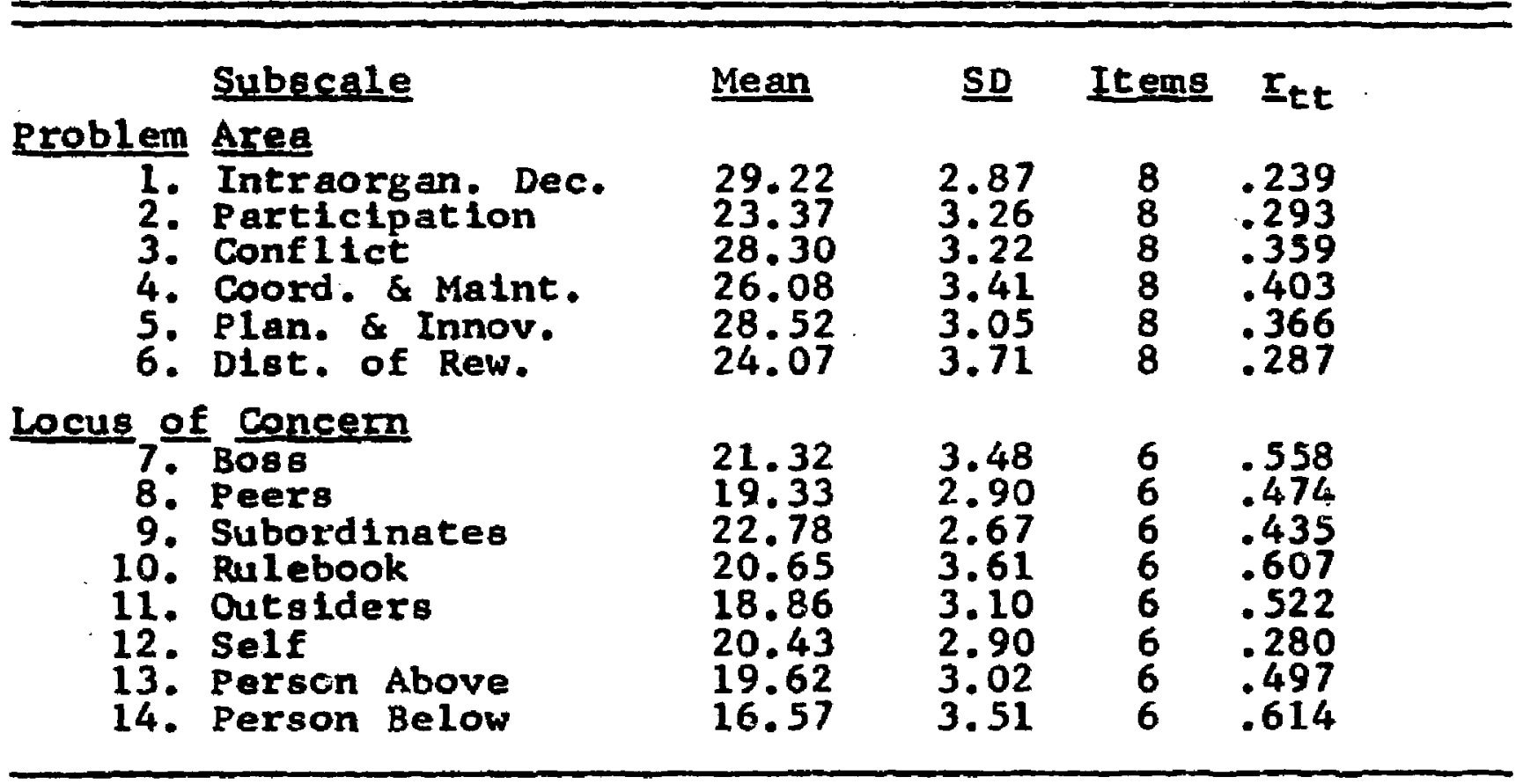


on each item were systematically reduced by the treatment of missing data. Group means were substituted for missing data; hence, all reliability estimates err in the conservative direction. Nevertheless, these reliabilities are much too low to be used for anything but large sample research.

\section{Factor Patterns}

The intercorrelation matrix for items 1 to 48 is shown in Appendix B. These correlations become interesting only in the 1ight of the factor analysis. In Table $V$ one finds the unrotated factor structure along with the communalities. The writer experimented with the extraction of factors and found seven to be a reasonable number, in terms of both mathematical significance and psychological meaning. The extraction of additional factors dropped off sharply at this point, as did the number of items defining the new factors. The communalities are not very large with this number of factors, but this is to be expected when dealing with items which are likely to contain a large amount of specific variance. To increase the average communality, one would have to extract many more factors which would have little psychological meaning or utility.

The results of a varimax rotation of the seven factors are shown in Table VI. The writer performed several other rotations using different combinations of factors, but this particular resolution proved to be the most satisfactory, according to the following criteria. This resolution most nearly satisfied the criteria of simple structure as set forth by Thurstone (1947), and it was the most interpretable in terms 
TABLE $V$

Unrotated Factor structure

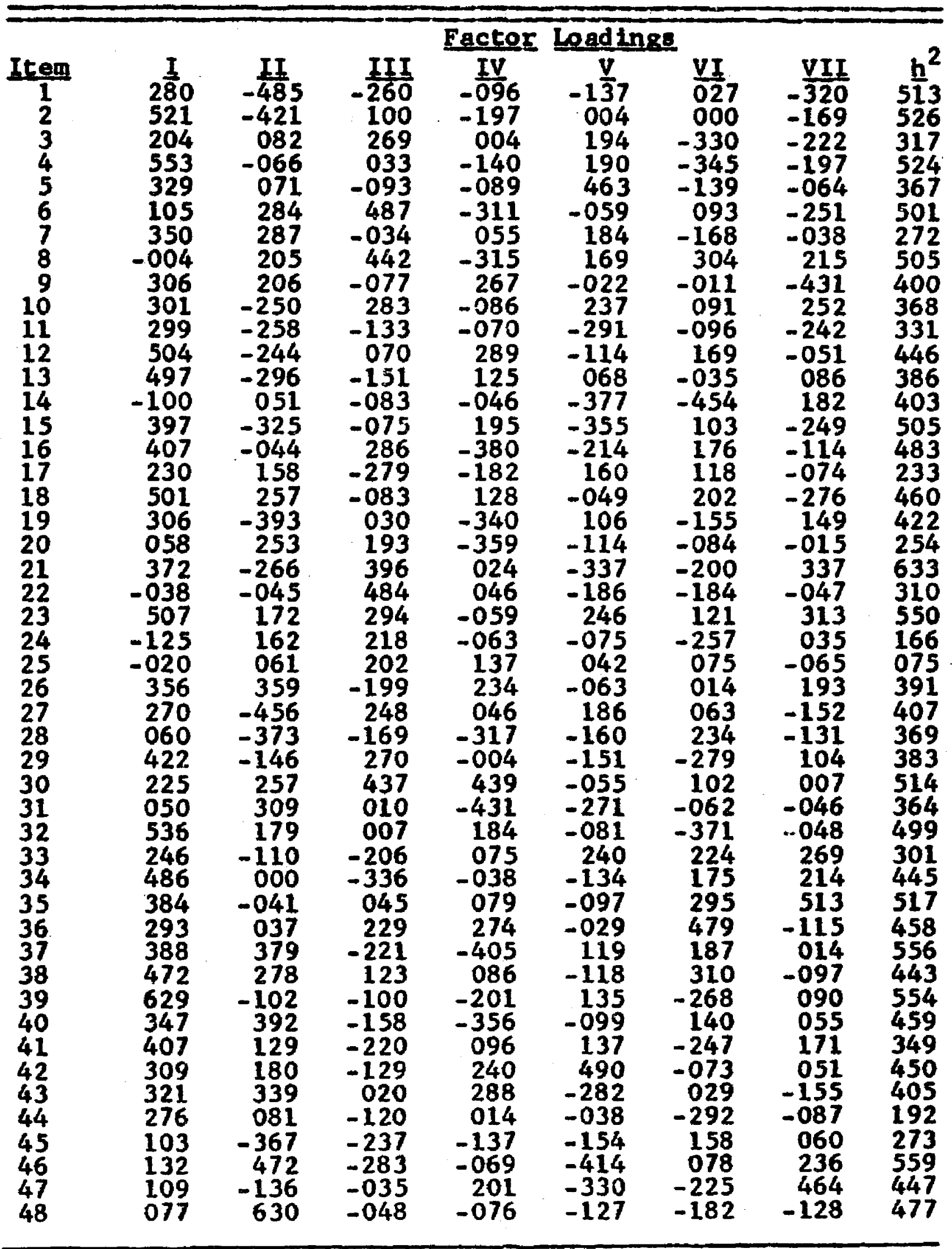


of psychological meaning. The mathematical intent of rotating to simple structure is to pass planes (or hyperplanss) through clusters of item vectors in order to maximize the number of near zero loadings (Fruchter, 1954). This manipulation maximizes the loading of a given item on a given factor and therefore reduces its loading on the other factors. The net effect of this procedura then is to produce a factor resolution which is relatively well-defined in that each factor contains a small number of high-loading items, and no item loads highly on more than one factor. One of the chief virtues of this method is the ease in interpretation which it provides.

The five factors which were most clearly defined were chosen to be used in scoring. These factors will be discussed In more detail in the Discussion section; however, the names given to the factors convey their psychological meaning as interpreted by the author. They are:

Factor I: Consideration for Subordinates

Factor II: Concern for Authority

Factor III: Regard for Self

Factor IV: Distribution of Reward

Factor V: General Organization Concern

\section{Analyses of Variance*}

Size of Department and Organization (1tems 1 and iii). The analysis of varlance between the different sizes of departments and organizations yielded no statistically significant differences in the subscale means or factor scores.

*The mean squares and the degrees of freedom for all of the analyses presented in the following tables may be seen in Appendix $C$. 
Length of Time Subject Has Directed His Department (item ii). Although there were no statistically significant differences related to this question, the means do show some trends worth reporting, as can be seen in Table VII. For example, the less seniority as head of a department, the greater concern was shown for subordinates on the part of those who have directed their departments less than 2 years as opposed to those who have been in charge for up to 10 years. The $F$ value in this case is very close to the 5 percent level of significance. The trends for Factors IV and V reveal that the longer one had directed his department, the less he was concerned about the distribution of rewards and the more he was concerned with relevant organizational matters and persons affecting them. This is reflected also in the means of subscales five and $s i x$ which indicate an increase with time in planning and innovating, but a decrease in concern with distribution of reward.

Length of Time in Organization (item iv). The scores on Factors IV and $V$ and on subscales five and six confirm the patterns described above with the length of time which the $S$ had directed his department. Table VIII shows the means and $F$ values. Also, the scores on Factor III approach the 5 percent level of significance with short-termers indicating a much greater regard for self than those who have been in the organization for several years. The mean scores on the participation subscale yielded significant differences $(p=.05)$, with those in the organization less than 12 months showing the greatest concern about their personal participation in organizational affairs. To complete this picture, the same group of 
TABLE VII

Partial Summary of Means and $F$ Values for Analyses of Variance of Time as Head of Department

Factor

I. Con, for Subor.

17.2

17.5

15.5

15.9

2.561

IV. Dist. of Rew.

7.0

6.5

6.6

5.7

1.142

v. Gen. Org. Con.

18.0

18.0

18.8

19.7

1.636

Subscale

5. Plan. \& Innov.

$28.0 \quad 28.2$

$29.4 \quad 29.5$

1.668

6. Dist. of Rew.

$24.5 \quad 24.5$

23.7

22.8

.827 
TABLE VIII

Partial Summary of Means and F Values for Analyses of Variance of Time in Organization

Factor

III. Reg. for Self $\quad \begin{array}{lllllll}2.5 & 2.3 & 1.1 & 1.8 & .8 & 2.124\end{array}$

IV. Dist. of Rew. $\quad \begin{array}{lllllll}7.8 & 6.9 & 6.1 & 7.0 & 5.6 & 1.862\end{array}$

$\begin{array}{llllllll}\text { V. Gen. Org. Con. } 18.0 & 18.4 & 18.3 & 18.4 & 19.2 & .246\end{array}$

Subscale

2. Participation $\begin{array}{lllllll}25.8 & 23.6 & 22.1 & 23.8 & 23.0 & 2.519 *\end{array}$

5. Plan. \& Innov. $27.9 \quad 28.1 \quad 28.2 \quad 29.0 \quad 28.3 \quad .574$

6. Dist. of Rew. $\quad \begin{array}{llllll}26.4 & 23.9 & 23.3 & 24.3 & 23.2 & 1.272\end{array}$

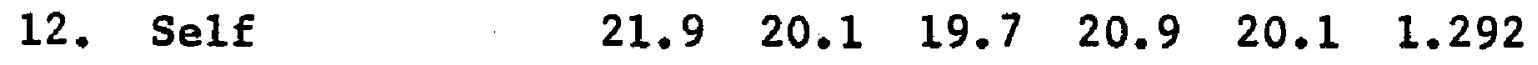

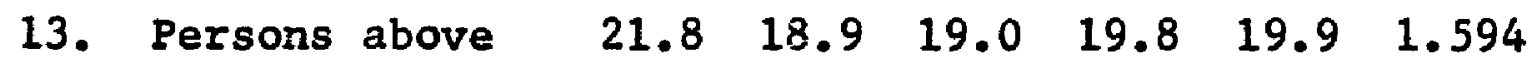

$*_{\mathrm{p}}=.05$ 
short-termers professed a greater regard for self and a greater tendency to consult with other persons above them in the organization as seen in subscales 12 and 13.

White vs. Blue-Collar (item v). Table IX shows the results of the comparisons among types of subordinates. This breakdown was one of the most discriminating of all those used in the analyses. Those Ss whose departments were composed of whitecollar workers professed to consult more with subordinates (Factor I) than those with blue-collar or mixed departments $(p=.01)$. On the other hand, those with blue-collar departments reported a greater concern for authority (Factor II) than either of the other two groups $(p=.01)$.

Those in both white and blue-collar departments showed more concern for general organizational phenomena (Factor V) than those in mixed departments $(p=.05)$. This latter difference is supported by scores on five of the six problem area subscales, white and blue-collar departments registering greater concern in each case. With regard to participation, this difference was quite substantial $(p=.01)$.

It is interesting to note that those in blue-collar departments registered a greater concern with conflict (subscale three) than either of the other two groups $(p=.05)$. The scores on subscales seven (Boss) and ten (Rulebook) add support to the differences found between the factor scores on concern for authority, the differences here belng statistically significant at the 5 and 1 percent levels, respectively. Similarly, the mean differences in scores on subscales nine (subordinates) and fourteen (others below) are in the same 


\section{TABLE IX}

Partial Summary of Means and $F$ Values for Analyses of Variance of Type of Subordinate

\begin{tabular}{|c|c|c|c|c|c|}
\hline & & \multicolumn{3}{|c|}{ Group Means } & \multirow{3}{*}{$\mathbf{F}$} \\
\hline & & $\begin{array}{l}\text { White- } \\
\text { Collar }\end{array}$ & $\begin{array}{l}\text { Blue- } \\
\text { Collar }\end{array}$ & $\begin{array}{l}\text { Mixed white } \\
\text { and blue }\end{array}$ & \\
\hline & $(\mathrm{N})$ & $(42)$ & $(21)$ & (17) & \\
\hline \multicolumn{6}{|c|}{ Factor } \\
\hline I. & Con. for Subor. & 17.3 & 16.6 & 14.6 & $5.311 * \star$ \\
\hline II. & Con. for Author. & 16.0 & 18.6 & 16.4 & $5.186 * \star$ \\
\hline V. & Gen. Org. Con. & 19.0 & 19.2 & 16.9 & $4.295^{\star}$ \\
\hline \multicolumn{6}{|c|}{ Subscale } \\
\hline 1. & Intraorg. Dec. & 29.5 & 30.0 & 27.2 & $6.004 * \star$ \\
\hline 2 & Participation & 24.0 & 23.1 & 22.3 & 2.026 \\
\hline 3. & Conflict & 28.0 & 30.0 & 27.8 & $3.077 *$ \\
\hline 4. & Coor. \& Main. & 26.5 & 26.7 & 24.6 & 2.226 \\
\hline 6. & Dist. of Rew. & 24.7 & 25.1 & 22.8 & 2.564 \\
\hline 7. & Boss & 20.9 & 23.3 & 20.4 & $4.537 *$ \\
\hline 9. & Subordinates & 23.4 & 23.2 & 21.1 & $5.150 * \star$ \\
\hline 10. & Rulebook & 20.3 & 23.3 & 20.2 & $6.529 * *$ \\
\hline 14. & Persons below & 17.4 & 16.0 & 15.0 & $3.308 *$ \\
\hline
\end{tabular}


direction as those on Factor I (consideration for subordinates) and are significant at the 1 and 5 percent levels, respectively. Skill Level of Department (item vi). This question attempts a finer breakdown than the preceding one but, in general, the results are the same, as can be seen in Table $X$.

Although the mean differences did not quite reach the 5 percent level of significance, those with semi-professional subordinates registered more consideration for subordinates than any of the other three groups. However, they reported less concern with authority $(p=.05)$.

On the subscale scores the same group showed less concern with conflict, less concern with boss, less concern with the rulebook $(p=.05)$ and more concern with persons below them in the organization other than their own subordinates.

Line or Production vg. Staff or Service (item vil). The only finding of interest with this breakdown was the difference $(P=.05)$ on the subordinate subscale. Although the difference was small, the line or production Ss $(X$ score $=23.6$ ) reported a greater concern for subordinates than the staff or service Ss $(\overline{\mathrm{X}}$ score $=22.3)$.

Boss--Intraorganizational Decisions (item 49). The factor scores which approached significance on this question were those on concern for authority. Table XI displays the results. Those persons who said they would merely "state their opinion" when disagreeing with the boss had a considerably lower mean score on Factor II, as they well should have.

The subscale scores on this item seem to indicate that these persons not only describe themselves as being relatively 
TABLE X

Partial Summary of Means and $F$ Values for Analyses

of Variance of Skill Level of Department

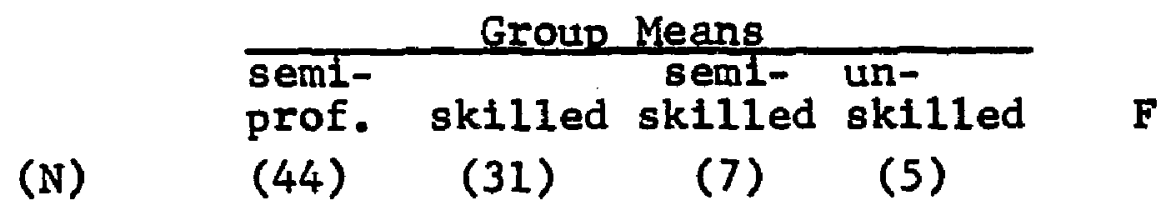

\section{Factor}

I. Con. for Subor. $\quad 17.2 \quad 15.5 \quad 16.9 \quad 16.2 \quad 2.139$

II. Con. for Author. $15.8 \quad 18.4 \quad 17.1 \quad 16.5 \quad 3.840 *$

\begin{tabular}{llllll}
\multicolumn{2}{l}{ Subscale } & & & & \\
3. Conflict & 27.7 & 29.4 & 29.1 & 29.2 & 2.012 \\
7. Boss & 20.6 & 22.7 & 22.3 & 20.8 & 2.456 \\
10. Rulebook & 19.6 & 22.6 & 21.4 & 21.8 & $5.118 * *$ \\
14. Persons below & 17.5 & 15.5 & 15.6 & 15.6 & 2.316 \\
\hline${ }_{*}=.05$ & & & & & \\
$*^{*} \mathrm{p}=.01$ & & & & &
\end{tabular}


TABLE XI

Partial Summary of Means and F Values for Analyses of Variance of Responses to Disagreement with Boss about Intraorganizational Decisions

\begin{tabular}{|c|c|c|c|c|c|}
\hline & & \multicolumn{3}{|c|}{ Group Means } & \multirow{3}{*}{$\mathbf{F}$} \\
\hline & & $\begin{array}{l}\text { state } \\
\text { my } \\
\text { opinton }\end{array}$ & $\begin{array}{l}\text { state my } \\
\text { opinton, } \\
\text { do what } \\
\text { the boss } \\
\text { says }\end{array}$ & $\begin{array}{l}\text { seek a } \\
\text { mutually } \\
\text { accept- } \\
\text { able } \\
\text { solution }\end{array}$ & \\
\hline & (N) & (8) & $(27)$ & (74) & \\
\hline \multicolumn{6}{|c|}{ Factor } \\
\hline II. & Con. for Author. & 14.0 & 16.9 & 16.7 & 2.604 \\
\hline \multicolumn{6}{|c|}{ Subscale } \\
\hline 2. & Participation & 21.5 & 22.9 & 23.8 & 2.200 \\
\hline 3. & Confilct & 26.0 & 28.3 & 28.6 & 2.341 \\
\hline 4. & Coor. \& Main. & 24.8 & 25.9 & 26.3 & .868 \\
\hline 5. & Plan. \& Innov. & 26.5 & 29.4 & 28.5 & 2.762 \\
\hline & Dist. of Rew. & 22.3 & 23.2 & 24.6 & 2.462 \\
\hline 7. & Boss & 19.4 & 21.7 & 21.4 & 1.459 \\
\hline 8. & Peers & 18.8 & 18.2 & 19.8 & $3.181 *$ \\
\hline 9. & Subordinates & 21.4 & 22.6 & 23.0 & 1.424 \\
\hline 10. & Rulebook & 17.0 & 21.1 & 20.9 & $4.699 *$ \\
\hline 13. & Persons above & 18.1 & 19.8 & 19.7 & 1.066 \\
\hline 14. & Persons below & 15.6 & 16.2 & 16.8 & .617 \\
\hline
\end{tabular}


Independent of authority, but they also express a general "don't care" attitude. On 11 of the 14 subscales, their scores are consistently lower than the other two groups. The greatest mean differences occurred on the subscales concerning conflict, planning and Innovation, and the rulebook $(p=.05)$.

Peers--Participation (item 50). Those people who indicated that they would follow their own dictates regarding participation (see Table XII) had significantly lower scores on conflict $(p=.05)$, boss $(p=.05)$ and persons above $(p=.05)$. They also showed a lack of concern about intraorganizational decisions and participation in organizational affairs. Although the $N$ of this group is sufficiently small so that the results probably should not be overdrawn, these seem to be a group of Individualists who will go their own way regardless of other pressures and influences within the organization.

Rulebook--Coordination and Maintenance of Departmental Activities (item 51). Three very different groups emerged from the responses to this item, as can be seen in Table XIII. Those who proposed to work around inflexible organizational policies showed a disregard for authority as evidenced by their low scores on Factor II, subscale seven and subscale ten $(p=.01)$.

Those who professed to stick with the status-quo and to hope Indicated a significantly lower concern with the distribution of rewards $(p=.05)$ and with other persons below them in the organization $(p=.05)$.

Those who would initiate remedial action reported a greater consideration of their subordinates (Factor $I-p=.01$ ) and a greater interest in general organizational matters (Factor V). 
TABLE XII

Partial Summary of Means and $F$ Values for Analyses of Variance of Responses to Disagreement with Peers about Participation

Subscale

\begin{tabular}{llllll} 
1. Intraorg. Dec. & 25.8 & 29.5 & 29.3 & 29.2 & 2.035 \\
2. Participation & 20.3 & 23.2 & 23.8 & 23.0 & 1.677 \\
3. Conflict & 24.0 & 28.9 & 28.5 & 27.8 & $3.253 \star$ \\
7. Boss & 18.0 & 22.7 & 21.4 & 20.0 & $3.185 \star$ \\
8. Peers & 16.8 & 20.0 & 19.4 & 17.2 & 2.612 \\
13. Persons above & 15.5 & 20.3 & 19.7 & 20.0 & $2.949 *$ \\
\hline
\end{tabular}

${ }^{*_{p}}=.05$

Group Means

Isten to consult re-exam-

them, but with my ine the try to
follow my boss, facts, conown then then vince dictates decide decide them
(5)
(N)

(26)

(67) 


\section{TABLE XIII}

Partial Summary of Means and F Values for Analyses of Variance of Reactions to Rulebook Interfering with Departmental Activities

\begin{tabular}{|c|c|c|c|c|c|}
\hline & & \multicolumn{3}{|c|}{ Group Means } & \multirow[b]{2}{*}{$F$} \\
\hline & & $\begin{array}{l}\text { work } \\
\text { around } \\
\text { them }\end{array}$ & $\begin{array}{l}\text { accept } \\
\text { the sit- } \\
\text { uation }\end{array}$ & $\begin{array}{l}\text { intitiate } \\
\text { remedial } \\
\text { action }\end{array}$ & \\
\hline & (N) & (9) & (35) & $(50)$ & \\
\hline \multicolumn{6}{|c|}{ Eactor } \\
\hline & Con. for Subor. & 15.1 & 15.8 & 17.6 & $5.649 * *$ \\
\hline & Con. for Author. & 14.2 & 16.8 & 16.9 & 2.619 \\
\hline & Dist. of Rew. & 7.3 & 5.9 & 7.0 & $3.430 *$ \\
\hline & Gen. Org. Con. & 16.9 & 17.9 & 19.0 & 2.726 \\
\hline \multicolumn{6}{|c|}{ Subscale } \\
\hline & Intraorg. Dec. & 27.6 & 28.5 & 30.4 & $8.425 * *$ \\
\hline 2. & Participation & 22.3 & 22.3 & 24.4 & $5.036 * \star$ \\
\hline 3. & Conflict & 25.2 & 27.3 & 29.4 & $9.480 * *$ \\
\hline & Coor. \& Main. & 24.1 & 25.4 & 26.8 & $3.606 *$ \\
\hline 8. & Peers & 18.6 & 18.4 & 20.2 & $4.383 *$ \\
\hline 9. & Subordinates & 21.3 & 22.2 & 23.5 & $4.520 \%$ \\
\hline 10 . & Rulebook & 17.3 & 20.5 & 21.5 & $5.285 * *$ \\
\hline 13. & Persons above & 18.3 & 18.8 & 20.3 & $3.755 *$ \\
\hline 14. & Persons below & 16.4 & 15.5 & 17.5 & $3.369 *$ \\
\hline
\end{tabular}

${ }^{*} \mathrm{p}=.05$
$*_{\mathrm{p}}=.01$ 
They showed a greater concern in all of the problem areas on the first six subscales, the mean differences being significant at the 1 percent level on the first three and at the 5 percent level on the fourth. On subscales 8,9 and 13, they reported greater concern for their peers $(p=.05)$, their subordinates $(p=.05)$ and those above them in the organization $(p=.05)$. Qutsiders--Planning and Innovation (item 53). Table XIV displays the results for this item. Subjects who object to tie intrusion of outsiders show less concern about their own participation in organizational affairs and about the coordination and maintenance of their departmental program. Although the difference is sma1l, they profess to consult less with outsiders. Those persons who claim to follow the suggestions of outsiders when they have the authority register a greater degree of consulting with persons in the organization above them other than their boss $(\mathrm{p}=.05)$.

Boss and Subordinates--Conflict (item 55). Table XV shows that Ss who profess to support their boss when a conflict exists between boss and subordinates score significantly higher than the other three groups on the self regard factor $(p=.01)$. They also register a greater concern for the distribution of rewards.

Boss--Conflict (item 56). Subjects who say the boss "pulls rank" on them or is completely unpredictable show a consistently different pattern of responses than those who hold a more favorable attitude towards their boss (see Table XVI). The former group is less considerate of subordinates and boss and is less concerned, in general, about organizational matters 
TABLE XIV

Partial Summary of Means and $F$ Values for Analyses of Variance of Reactions to Outsiders Attempting to Influence Planning

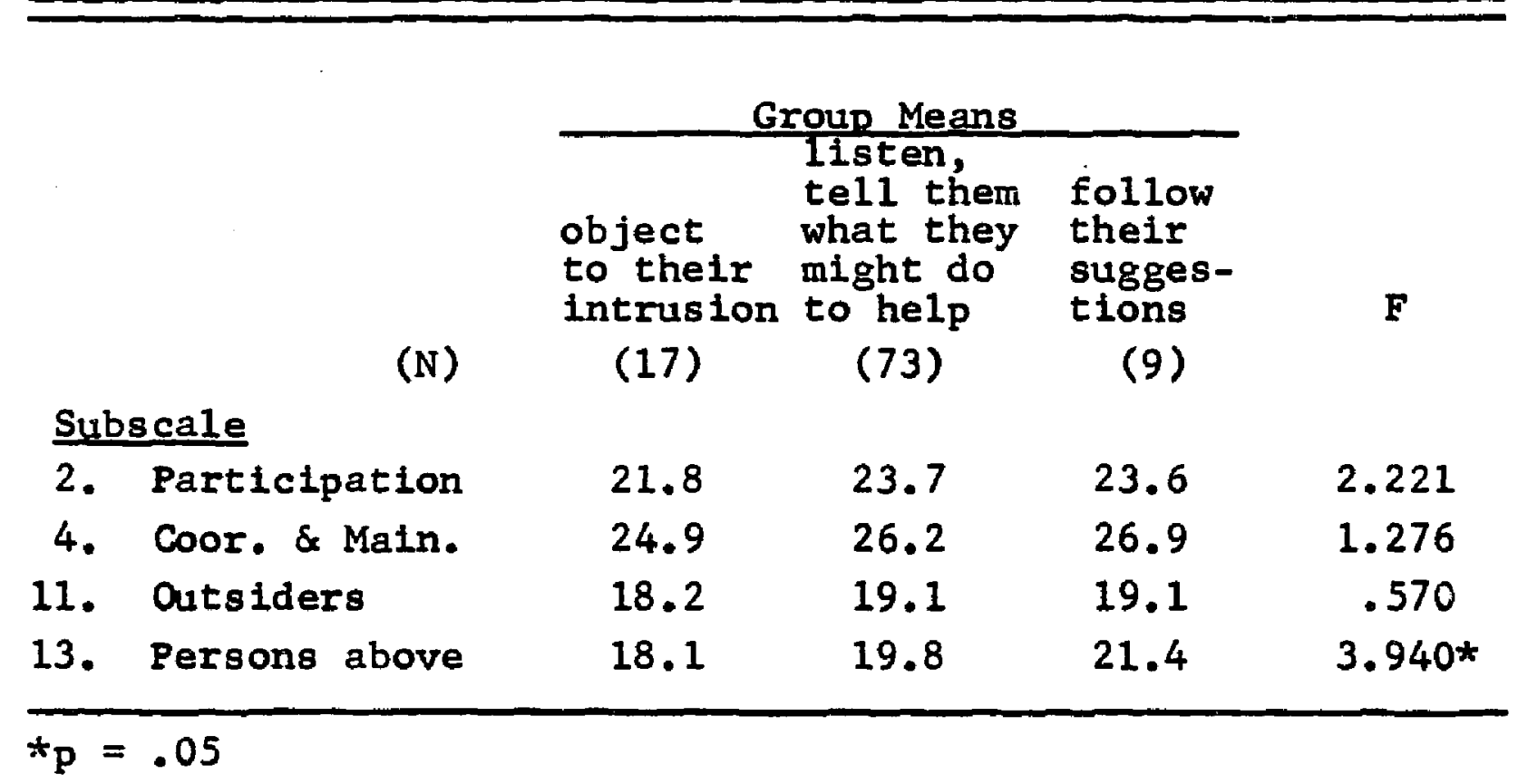


TABLE XV

Partial Summary of Means and F Values for Analyses

of Variance of Reactions to Boss--Subordinate Conflict

\section{Eactor}

$\begin{array}{rrrrrl}\text { III. Reg. for Self } & .9 & .4 & 4.2 & 2.0 & 4.958 * * \\ \text { IV. Dist. of Rew. } & 6.0 & 6.0 & 8.0 & 7.0 & 1.980\end{array}$

Subscale

8. Peers

18.4

18.0

20.8

$20.02 .947 *$

${ }^{\star} \mathrm{p}=.05$

$\star^{*} p=.01$ 
TABLE XVI

Partial Summary of Means and $F$ Values for Analyses of Variance of Descriptions of Boss' Behavior in Conflict

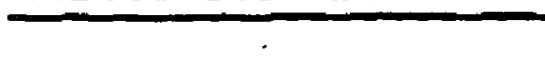

\begin{tabular}{|c|c|c|c|}
\hline $\begin{array}{l}\text { pulls } \\
\text { rank } \\
\text { on me }\end{array}$ & $\begin{array}{l}\text { tries to } \\
\text { convince } \\
\text { me }\end{array}$ & $\begin{array}{l}\text { seeks a } \\
\text { mutually } \\
\text { satis- } \\
\text { factory } \\
\text { decision }\end{array}$ & $\begin{array}{l}\text { is com- } \\
\text { pletely } \\
\text { unpre- } \\
\text { dict- } \\
\text { able }\end{array}$ \\
\hline
\end{tabular}
(N)
(8)
(23)
(66)
(6)

Factor

I. Con. for Subor. $\begin{array}{lllll}15.3 & 17.3 & 16.9 & 15.3 & 1.009\end{array}$

II. Con, for Author. $15.3 \quad 17.1 \quad 16.8 \quad 14.5 \quad 1.133$

v. Gen. Org. Con. $16.3 \quad 18.4 \quad 18.8 \quad 17.5 \quad 2.527$

Subscale

1. Intraorg. Dec. $27.0 \quad 29.8 \quad 29.6 \quad 27.5 \quad 3.062 *$

4. Coor. \& Main. $23.8 \quad 26.7 \quad 26.3 \quad 24.8 \quad 1.854$

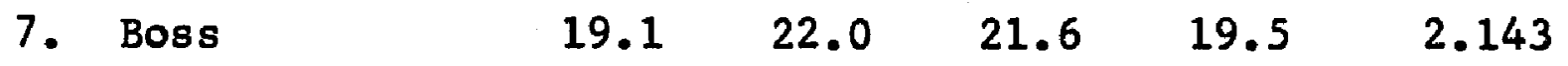

$\begin{array}{llllll}\text { 8. Peers } & 16.1 & 19.6 & 19.8 & 18.2 & 4.820 * \star\end{array}$

$\star_{p}=.05$

$\star^{*} \mathrm{p}=.01$ 
$(p=.05)$. They consult less with boss and peers $(p=.01)$ about the coordination and maintenance of their department. Satisfaction of Subordinates (item 57). Those Ss who reported their subordinates to be moderately dissatisfied scored the highest of all four groups on Factor $v$, general organizational concern, as can be seen in Table XVII. They also indicated a greater concern for the coordination and maintenance of their departmental program and for planning and Innovation $(p=.01)$. They professed to consult more with their boss and other persons above them in the organization although these differences were not statistically significant.

The group which claimed that their subordinates were completely satisfied with their jobs showed the greatest concern of any group for organizational policy $(p=.05)$.

Productivity of Department (item 58). The analysis based on this item yielded no statistically significant differences.

Levels in the Organization. Table XIII shows that there was a highly significant difference among the three levels regarding concern for authority. The highest level group showed the least regard for authority and the lowest level group showed the most $(p=.01)$. The same differences existed on the boss subscale $(p=.01)$ and with regard to rulebook. The highest level also showed less concern with the distribution of rewards.

Departments in the Organization. Table XIX displays the results of the analysis among the five departments. The Ss from Engineering departments registered a high degree of 
TABLE XVII

Partial Summary of Means and $F$ Values for Analyses of Variance of Satisfaction of Subordinates

\begin{tabular}{|c|c|c|c|c|c|c|}
\hline & \multirow[b]{3}{*}{$(\mathrm{N})$} & \multicolumn{4}{|c|}{ Group Means } & \multirow[b]{2}{*}{$\mathbf{F}$} \\
\hline & & $\begin{array}{l}\text { com- } \\
\text { pletely } \\
\text { satis- } \\
\text { fled }\end{array}$ & $\begin{array}{l}\text { moder- } \\
\text { ately } \\
\text { satis- } \\
\text { fled }\end{array}$ & $\begin{array}{l}\text { neither } \\
\text { satis- } \\
\text { fled } \\
\text { nor } \\
\text { dissat. }\end{array}$ & $\begin{array}{l}\text { moder- } \\
\text { ately } \\
\text { dissat. }\end{array}$ & \\
\hline & & (23) & (63) & (9) & (6) & \\
\hline \multicolumn{7}{|c|}{ Factor } \\
\hline & Gen. Org. Con. & 18.5 & 18.1 & 18.4 & 19.7 & .655 \\
\hline \multicolumn{7}{|c|}{ Subscale } \\
\hline 4. & Coor. \& Main. & 26.9 & 25.6 & 25.2 & 28.3 & 1.878 \\
\hline 5. & Plan. \& Innov. & 29.7 & 27.6 & 28.8 & $32 \cdot 3$ & $7.186 * *$ \\
\hline 7. & Boss & 21.8 & 21.1 & 19.8 & 23.3 & 1.504 \\
\hline 10. & Rulebook & 22.7 & 20.3 & 19.2 & 21.5 & $3.178 *$ \\
\hline 13. & Persons above & 20.3 & 19.4 & 18.1 & 21.7 & 2.235 \\
\hline
\end{tabular}


TABLE XVIII

Partial Summary of Means and $F$ Values for Analyses of Varlance of Levels in Organization

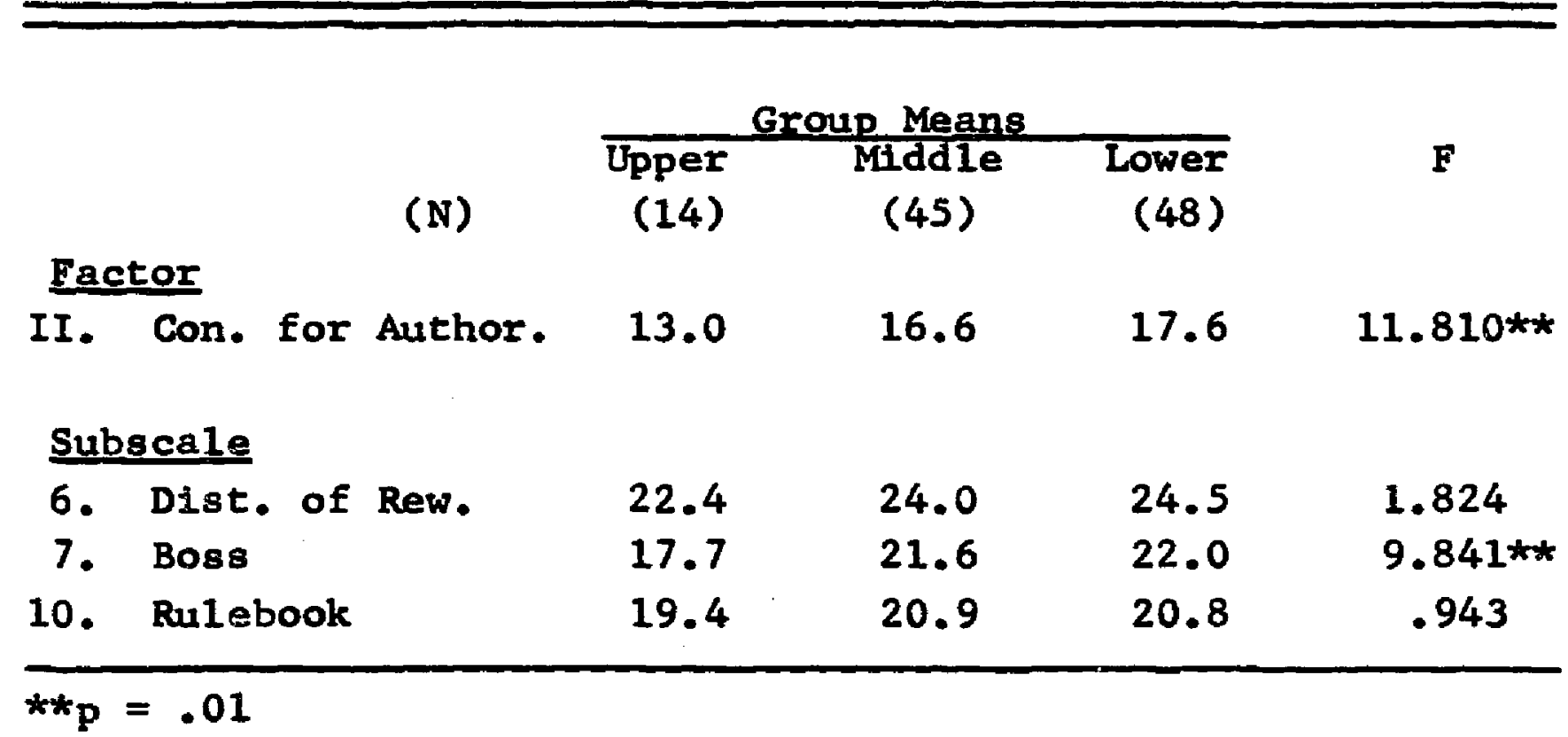


TABLE XIX

Partial Summary of Means and $F$ Values for Analyses of Variance of Departments in the Organization

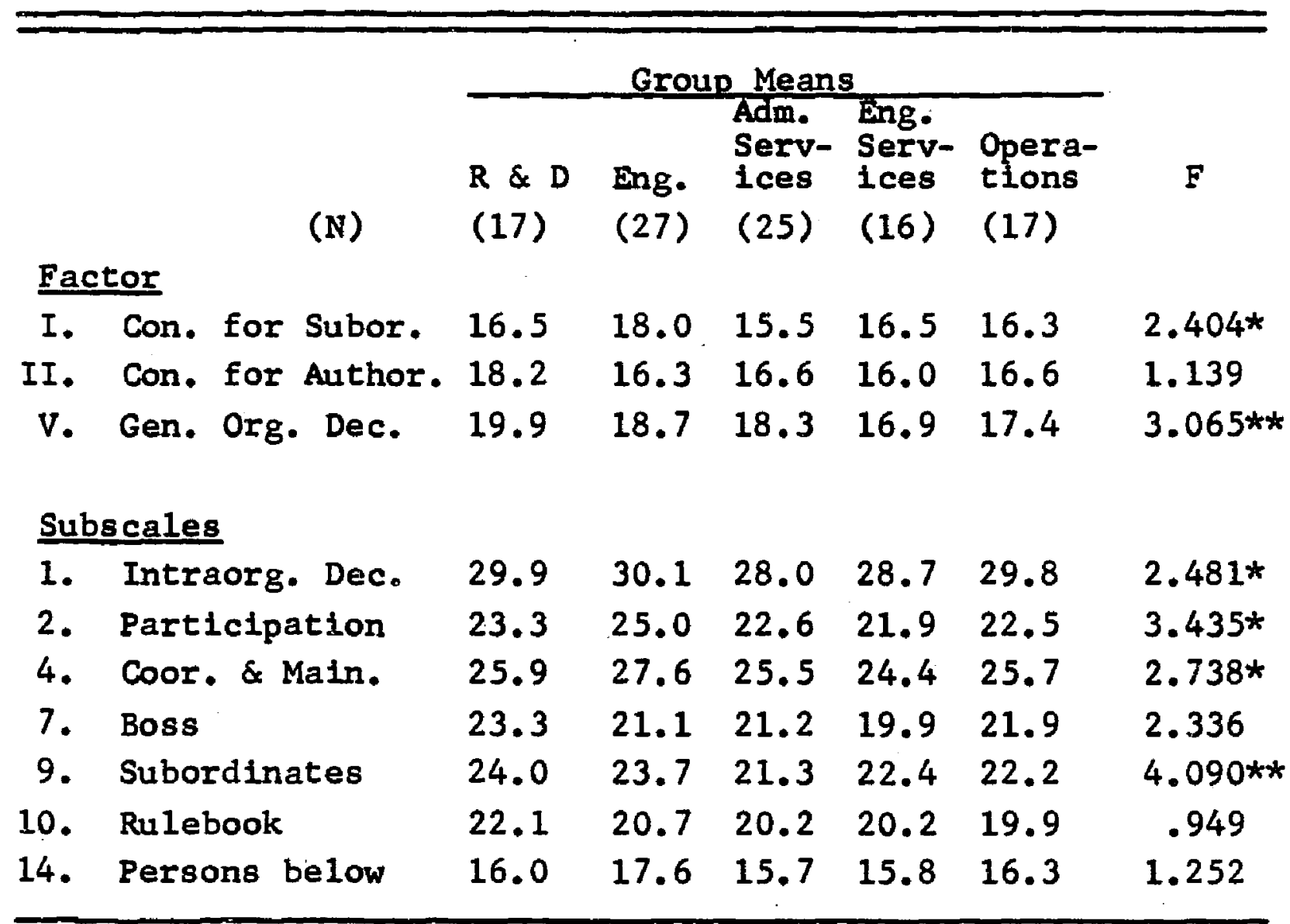

${ }^{*} \mathrm{p}=.05$

$\star \star p=.01$ 
consideration for subordinates (Factor $I, p=.05$, subscale 9 , $p=.01)$. They also showed marked concern for intraorganizational decisions $(p=.05)$, their own participation in organizational matters $(p=.05)$ and the coordination and maintenance of their departmental activities $(p=.05)$. Consistent with their tendency to consult their own subordinates was their more frequent reported consultation with other persons below then in the organization.

In every instance cited above, the Ss from administrative service departments were on the opposite end of the continuum.

The Ss from $R$ \& D departments reported a significant amount of consultation with their subordinates as measured by the subscale score $(p=.01)$. However, they also showed a consistent concern for Authority as measured by Factor II and subscales seven and ten. Theirs was the highest score on Factor $v$, general organizational concern $(p=.01)$. 


\section{DISCUSSION}

Self-Descriptive Technique

Before proceeding with the discussion of the results, an additional word about the nature and limitations of the selfdescriptive technique is in order. As a group, self-descriptive instruments are typically lower in rellability than other measuring devices, and PAR is no exception. Language difficulties, smal1 numbers of items and the problem of internal consistency are three of the chief factors contributing to this low reliability.

The question of validity also presents spectal problems with the self-descriptive questionnaire. Face validity is most often claimed for these instruments; however, face validity is a problem in itself in that the subject can and often does direct his responses towards his own ends when the intent of the questionnaire is obvious.

Nunnally (1959) points out that the most effective use of self-descriptive techniques is in research studies and not as instruments to evaluate people. It should be made clear that the author would in no sense defend the reliability or validity of the present questionnaire as an individual assessment tool. It is specifically intended to be a large-scale survey instrument, and as such, probably has adequate reliability and validity. It has considerable construct validity 
on the basis of the relationships between these results and previous findings, and the probability that it will prove to have significant factorial validity is very high, considering the nature of the factors extracted.

In view of the above limitations then, the author would caution the reader against attaching too much importance to specific, individual results and suggests instead that he focus on the consistent group differences and trends.

Consideration for Subordinates

Factor I is very clearly defined as consideration for one's own subordinates and others below him in the organization by the following items.

Item Factor I: Consideration for Subordinates Loading

*30 Subordinates--Coord. \& Main. 60

*36 Subordinates--Intraorg. Dec. 60

*38 Persons Above--Intraorg. Dec. 57

*43 Persons Below--Participation 54

*18 Persons Below--Coord. \& Main. 53

9 Persons Below--Conflict 45

12 Subordinates--Participation 44

*Incilcates items used in scoring

Al1 but one of the seven highest loadings are on items belonging to this group, and all but one of the problem areas are represented. This factor is probably closely related to the same dimension as the consideration factor found in the Ohio State Leadership studies (Stogd 111 \& Coons, 1957). The individual who scores high on this factor professes to consult with his subordinates and others below him on virtually all matters of Importance.

Stogdil1 \& Coons (1957) found a negative relationship 
between effectiveness ratings by superiors and consideration scores of alr crew commanders. Crew satisfaction, however, was highly related to the consideration index. They conclude that consideration seems to be a form of behavior which contributes toward crew morale rather than making a direct contribution to effectiveness.

In other studies, consideration of subordinates has been found to bear a significant positive relattonship to high producing departments (Katz, et al., 1951; Kahn, 1956).

A study by Mann \& Dent (1954b) reports that supervisors rated "immediately promotable" by their superiors were seen by their subordinates as members of their own work group. These supervisors had apparently created atmospheres of free discussion with their men. They let them know where they stood and frequently discussed problems with the entire group.

\section{Concern for Authority}

The dominant appearance of boss and rulebook items on Factor II indicates a marked concern for authority.

$\begin{array}{llc}\text { Item } & \text { Factor II: Concern for Authority } & \text { Loading } \\ * 1 & \text { Boss--Plan. \& Innov. } & 69 \\ \star 2 & \text { Rulebook--Participation } & 60 \\ * 15 & \text { Rulebook--Intraorg. Dec. } & 58 \\ * 11 & \text { Boss--Coord. \& Main. } & 53 \\ * 28 & \text { Boss--Dist. of Rew. } & 51 \\ 45 & \text { Rulebook--Plan. \& Innov. } & 37 \\ 19 & \text { Boss--Intraorg. Dec. } & \end{array}$

Again, the concern is a very general one, as all but one of the problem areas are represented. The individual who scores high on this factor consults some higher authority when making 
virtually all decisions.

According to a study by Morse (1953), traditional management would look favorably on a high score on this factor. He found that in describing what they wished their supervisors to do, higher levels of management placed even less emphasis than supervisors on "pulling for the men or both the men and the company" and more emphasis on "pulling for the company."

Moreover, this factor reflects the classical task-oriented and authority-oriented conception of management expounded in the 1920's and practiced in most companies and governmental agencies today. This is the tradition stemming from F. W. Taylor and others and described by McGregor (1960) as Theory X. In brief, it is a philosophy of management by direction and control. The assumptions on which it is based are static and fail to take adequate account of the rich motivational properties and basic capabilities of the individual.

Regard for Self

While the loadings are not as high on Factor III as might be desired, the pattern is still clear as can be seen below in the reflected loadings.

$\begin{array}{llc}\text { Item } & \text { Factor III: Regard for Self } & \text { Loading } \\ * 22 & \text { Self--Dist. of Rew. } & +50 \\ \star 34 & \text { Boss-Participation } & -52 \\ * 37 & \text { Persons Below-Dist. of Rew. } & -43 \\ 33 & \text { Peers--Intraorg. Dec. } & -42 \\ 46 & \text { Outsiders--Coord. \& Main. } & -41 \\ & \text { *Indicates items used in scoring }\end{array}$

It 1s, quite simply, selfishness; 1 .e.., regard for self and rejection of all others. The high scorer on this factor 
considers only himself when making decisions that affect all of those who work with him.

Distribution of Reward

The dominant theme for Factor IV is distribution of reward. The following loadings have been reflected.

Item Factor IV: Distribution of Reward Loading

*31 Persons Above--Dist. of Rew. 59

$\star 40$ Peers--Dist. of Rew. 54

*37 Persons Below--Dist. of Rew. 50

*Indicates items used in scoring

Al1 three levels within the organization are represented with the problem area remaining the same. This is the first factor in which the problem area assumes more inportance than the locus of concern.

General Organizational Concern

Factor V represents a general organizational concern as shown by the following items.

Item Factor V: General Organizational Concern Loading

* 4 Peers--Coord. \& Main. 63

*39 Boss--Conflict 58

*32 Persons Below--P1an. \& Innov. 58

5 Outsiders--Intraorg. Dec. 51

*41 Outsiders--Conflict 50

*42 Subordinates--Plan. \& Innov. 50

*Indicates items used in scoring

In the six highest loadings, one finds all classes of loci of concern with the exception of the rulebook and all problem areas, save the distribution of reward. This is probably the most desirable factor pattern of all from the standpoint of current 
thinking about good management. A high score on this factor represents: a willingness to consult with and learn from peers when coordinating and maintaining one's own departmental activities; a tendency to bring conflict situations out into the open with the boss rather than attempt to hide them; a consideration for outsiders when they might be affected by intraorganizational matters; and finally, the inclusion of immediate subordinates and others below oneself in the organization in making plans and changes which are likely to affect al1.

Factor $V$ represents a rational approach to the problems of supervision in that there is a pattern of open communication with the appropriate locus of concern when dealing with different problems in the organization. This is in sharp contrast with Factors I, II and III in which attention was directed upward, downward or at oneself, respectively, regardless of the nature of the problem under consideration.

Factors VI and VII were not as clearly defined as the above, and therefore, were not used in further analysis.

Time With the Organization and Distribution of Rewards

Psychologists have made much of the finding that wages and monetary rewards do not play as important a role in worker satisfaction as many believed. Herzberg, et al., (1957) reviewed 150 studies and reported that several factors, including job security, intrinsic interest, opportunity for advancement, appreciation from supervisors, and company and management, ranked ahead of wages. However, Stuhr (1962) reports that 
starting salary, not the company's reputation or opportunity, was the deciding factor in determining whether or not professional and technical job candidates accepted appointments with one large company.

While this study did not investigate this question directly, the following findings do seem to be relevant. The analyses of items ii and iv indicate that wages assume considerable importance in one's early years on a job, but as time passes they decrease in importance. Bass' (1960) distinction between job attraction and job satisfaction is probably relevant here. One's attraction to a job is defined by the rewards he expects to receive from it, while job satisfaction is determined by the degree to which the job actually is rewarding to the individual. It may be then that monetary rewards are extremely 1mportant in determining job attractiveness prior to and in the early stages of the job, but that in the long run they play a lesser role in determining job satisfaction.

White vs. Blue-Collar Subordinates

The differences found between those Ss with white-collar departments and those with blue can be explained in part by the trends described in the Introduction. The former group reported significantly more consulting with subordinates while the latter paid more attention to the rulebook and their boss. One might speculate that the Ss from white-collar departments probably have been "enlightened" by management training programs more than those in blue-collar departments so that they have a greater appreciation of the importance of frequent, open communication with subordinates about matters which concern them. While 
this may be the case, the author submits that a part of the difference is attributable to the very nature of the subordinates. The relatively young professionals and semi-professionals in the white-collar departments represent the group on which the rapid progress in education and technology described earlier has had the greatest impact. As Individuals and as a group, they expect and demand more than a mere slot in the organization. They possess important knowledge and ideas which they worked hard to acquire, and they want to be able to comminicate them to their superiors at will. Moreover, the complex nature of their jobs requires a greater degree of interpersonal interaction, upward, downward and with peers.

Those Ss with blue-collar departments, on the other hand, have yet to break away from the traditional philosophy of management. They are still under the influence of the thinking characterized by Haire (1956) in the following quote: "The men in the work force don't ever give a thought to ways to do their jobs better." The human relations problems generated by this approach are reflected in the signiflcantly greater concern for conflict reported by these Ss.

These results also relate to what Etzioni (1961) refers to as the compliance system. By this he means the "relationship consisting of the power employed by superlors to control subordinates and the orientation of the subordinates to this power." The blue-collar worker is still controlled to a great degree by remuneration, hence the greater concern reported by Ss with blue-collar departments for distribution of rewards and the authority structure. In a very real sense the 
supervisors in these departments are forced to pay more attention to their boss and formal organtzational sanctions than to the problems of their subordinates. The white-collar worker, on the other hand, is influenced to a much greater extent by normative controls such as status and esteem. He is less threatened by authority, has more control over his own remuneration, and consequently is freer to gain satisfaction from other aspects of his job, e.g., being considerate of his subordinates.

Research relating effective interpersonal relationshtps with productivity has produced both positive and negative results. It is well established that good interpersonal relationships and happy subordinates by no means guarantee high productivity or the most effective organization. On the positive side of the ledger, however, Likert (1961) sumnarizes a number of studies which support the theory that better interpersonal relationships, developed by effective leadership, are positively associated with more effective, high-producing work groups. A prime means of achieving this effectiveness has been for the supervisor to demonstrate to his subordinates that their opinions are valued by consulting frequently with them on matters that affect their welfare and acting on their recommendations (Mann \& Dent, 1954a; Katz \& Kahn, 1951; Coch \& French, 1958). In the light of these findings then, the present data quite clearly favor those persons with white sollar departments.

Hypothesis two was confirmed on the basis of the results from both items $v$ and $v i$. The prediction was that the tendency to consult with subordinates would be greater in departments 
that were essentially semi-professional or skilled rather than semi-skilled or unskilled.

Concern for Authority and the Linking Pin Function

Much of the discussion to this point has emphasized the importance of consideration for subordinates. However, if one views the levels in the organization as a continuum from subordinates through superiors, then to swing too far towards the lower end of the continuum at the neglect of the higher can be just as damaging as the opposite pattern. Likert (1961) summarizes evidence by Pelz (1952) and others, showing that the amount of influence which a supervisor feels he has with his own superiors affects his ability to supervise his own subordinates effectively. When a supervisor is unable to exert sufficlent influence upward in the hierarchy he is likely to experience an unfavorable reaction from his subordinates against him and the organization in general.

Likert describes this capacity to exert influence upward as the linking pin function and makes it the cornerstone of his theory of management. The linking pin function provides a means of interaction between levels in the organization via overlapping groups. Likert holds this to be the key to effective organizations.

The analysis of items 49 to 56 uncovered several groups of Ss who seem to have a very low concern for the hlerarchy above them which, to Likert's way of thinking, is a dangerous situation for the organization. For example those $S$ s who said they would merely "state their opinion" when disagreeing with 
the boss about interdepartmental matters scored the lowest of all groups on the authority factor. Moreover, they express a general lack of concern on virtually all of the subscale scores: This pattern is consistent to the degree that it is likely to be unhealthy for the organization.

Again, those Ss who indicated they would "follow their own dictates" concerning their personal participation in organizational affairs showed a simtlar pattern to that described above. It is extremely unlikely that Ss showing this kind of pattern could serve Likert's linking pin function in their organization.

\section{Initiation}

Those Ss who claimed that they would initiate remedial action when faced with constraining organizational policies in the running of their departments show a pattern of responses which is literally at the opposite end of the continuum from those described immediately above. The other two groups on this item would "work around the policies" or "stick with the status quo." On 11 of the 19 sets of scores evaluated, the initiators showed statistically significant, greater concern or consultation than the other two groups. From an enlightened management's point of view this pattern of responses is probably the most desirable of any shown in all of the analyses. There is a somewhat equitable balance struck between concern for persons at all levels of the organization and emphasis on organizational phenomena. 


\section{Conflict}

Those Ss who claim to support their boss whenever he is in conflict with their subordinates score significantly higher on the self regard factor than those who would "act as a mediator" or "support whoever they think is right." These results confirm the laboratory findings from a simulation of the man-in-the-middle by Bass and Vaughan (1962). When caught In a conflict between boss and subordinates, self-ortented Ss, as measured by Bass' Orientation Inventory, focused significantly more communication upward, while task-oriented subjects focused more messages downward.

When in direct conflict with their boss those $\mathrm{Ss}$ who reported that the boss often "pulled rank" on them or was completely unpredictable reported less concern for authority and peers than those who reported the boss to be more reasonable in the situation. They also had lower scores on consideration for subordinates and less concern for general organizational matters. These data provide partial support for hypothesis three which stated that the tendency to consult with one's boss will correlate positively with tendency to consult with peers but negatively with tendency to consult with subordinates. In this particular instance the tendency was for those who held a favorable attitude towards their boss to consult with all three levels. This same pattern was reported with the initiators (item 51); however, the predominant pattern was one of elther high concern for boss and low for subordinates or vice versa.

On the basis of these same data hypothesis five must be 
rejected. It stated that those who felt their boss to be coercive would consult more with peers and persons above them in the organization other than the boss. The above results show just the opposite of this prediction.

Estimation of Subordinate Satisfaction

The only result of note in regard to the Ss' estimate of their subordinates' satisfaction is the pattern shown by those who reported their subordinates to be moderately dissatisfied (the lowest estimate made). They had the highest scores on the general organization factor and the related subscales. One might speculate that theirs is the most accurate estimate of a11.

Hypothesis four, positing a positive relationship between degree of consultation with subordinates and estimation of their satisfaction was not confirmed.

\section{Levels in the Oxganization}

The analysis of scores by levels in the organization produced a highly significant trend on the authority factor and on the boss and rulebook subscales. Those Ss in the upper level scored the lowest while those in the lower levels scored the highest. These results add support to those found with white vs. blue-collar departments.

The above discrepancy between the upper and lower levels gives evidence of a basic communication problem between the two. Those at the lower level often have too much respect for authority and even are awed by it to the extent that they are 
unable to communicate effectively with those above them. Those at the upper levels, on the other hand, because of their relatively stable and secure positions towards the top of the hlerarchy often fall to take adequate account of this barrier to effective comminication.

Departmenta1 Differences

Some interesting differences emerged from this analysis. The Ss in the engineering departments scored significantly higher on consideration for subordinates than those in other departments. In the light of the other findings in this study this is not a surprising result, but it would have been, as little as ten years ago. Engineers typically have been thought of as non-"human relations" types. In recent years, however, they have been moving more and more into managerial levels and have been gradually losing some of their past reputation. These data indicate that they now represent a new breed of managers who are especially sensitive to the need for effective interpersonal relations with their subordinates.

The Ss in research and development showed a pattern of responses fairly similar to engineering, while the Ss in administrative services were at the opposite end of the continuum.

Implications for Future Research

The next step in the study of the man-in-the-middle indicated by the present investigation ought to be to test the stability of the factors and patterns which emerged. 
This is a two-fold proposition. The first part asks the question, "will the same patterns emerge when the same instrument is administered to a totally different population?". The second part concerns the question, "will the same pattern emerge when a totally different instrument is administered to the same population?".

A second direction for future study might be the comparison of the man-in-the-middle's description of his actual behavior to his preferred behavior and/or to the description of his actual behavior by other persons in the organization. 


\section{SUMMARY AND CONCLUSIONS}

The purpose of the study was to seek patterns in the way in which the men-in-the-middle in a particular organization describe with whom they consult when faced with different organizational problems.

The Pittsburgh Administrative Review, a self-descriptive questionnatre, was adminlstered to 109 supervisors from a large industrial organization involved in the manufacture of 1iquid rockets. Fourteen subscale scores on specific problem areas and loci of concern were computed and subsequently submitted to a series of analyses of variance, grouped on the basis of the Ss' responses to eight objective and ten subjective questions on PAR. A factor analysis was performed on the 48 items used in obtaining subscale scores, and factor scores were computed for each $S$. These scores were also submitted to an analyses of variance, grouped as described above.

Five well-defined factors resulted from the factor analysis. The first was Consideration of Subordinates which appears to be very similar to the consideration factor on the Ohio state Leader Behavior Description Questionnaire. The second was a Concern for Authority which, in the main, was negatively related to the first. The third, Regard for Self, and the fourth, Distribution of Reward, represent concern for one's own welfare. The fifth, General Organizational Concern, is 
seen as the most rational of all the factor patterns.

Supervisors with white-collar subordinates reported a significantly higher degree of consulting with subordinates, while those with blue-collar workers claimed to consult more with the boss.

In general, the higher the supervisory level of the Ss, the less concern for authority they reported.

Supervisors who reported an extremely low concern for authority also showed a general lack of concern for most other organizational matters.

Engineering supervisors showed a significantly greater degree of consideration for subordinates than those in other departments.

The patterns of behavior described in the present study offer evidence of significant changes in supervisory behavior in certain areas, but at the same time, they indicate that the classical philosophy of management expounded by Taylor and others is still very much with us. 
REFERENCES

Argyris, C. Personality and Organization. New York: Harper, 1957.

Barnes, L. B. Orsanizational Systems and Engineering Groups: A Comparative Study of Two Technical Groups in Industry. Boston: Division of Research, Harvard Business School, 1960.

Bass, B. M. Leadership, Psychology, and Organizational Behavior. New York: Harper, 1960.

Bas8, B. M. \& Vaughan, J. A. Experimenting with the Man-InThe-Middle of the Organization. University of pittsburgh, 1962 (Paper presented at the Ford Foundation Seminar).

Bendig, A. W. "IBM 7070 Item Analysis Program," Behav. Sci., III $(1962 a)$, in press.

"IBM 7070 Program for Principle Axis Factor Analysis," Behav. Sci., VII (1962b), 126-127.

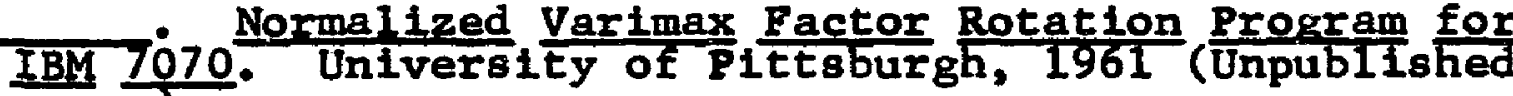
paper).

Blau, P. M., \& Scott, W. R. Formal Organizations, A Comparative Approach. San Francisco: Chandier Publishing Company, 1962 .

Brooks, E. "What Successful Executives Do," Personne1, XXXII (1955), 210-225.

Cattel1, R. B. Factor Analys1s. New York: Harper, 1952.

Coch, L., \& French, J. R. P., Jr. "Overcoming Resistance to Change," Human Relat., I (1958), 512-532.

Dalton, M. "Managing the Managers." In Rubenstein, A. H., \& Haberstroh, C. J. Some Theories of Organization. Homewood, I11.: Dorsey Press, Inc., 1960.

Downie, N. M. Fundamentals of Measurement: Techniques and Practices. New York: Oxford University Press, 1958. 
Dubin, R. "Psyche, Sensitivity, and Social Structure." In Tannenbaum, R., Weschler, I. R., \& Massarick, F. Leadership and Organization: A Behavioral Science Approach. New York: McGraw-Hill Book Co., Inc., 1961.

Etzioni, Amital. Complex Organizations. New York: The Free Press of Glencoe, Inc., 1961.

Fruchter, B. Introduction to Factor Analysis. New York: D. Van Nostrand Co., Inc., 1954.

Gilmer, B. von Haller. Industrial Psychology. New York: MeGraw-H111 Book Co., Inc., 1961.

Haire, M. Bsychology in Management. New York: McGraw-Hill Book Co., Inc., 1956 .

Halpin, A. W. "The Leader Behavior and Effectiveness of Aircraft Commanders." In Stogdill, R. M. \& Coons, A. E. (Eds.) Leader Belyvior: Its Descrintion and Measurement. Bur. Bus, Res. Monogr. 88, Ohio State Univ., Columbus, 1957.

Herzberg, F., Mausner, B., Peterson, R. O., \& Capwel1, D. F. Job Attitudes: Review of Research and Optnion. Pittsburgh: Psychological service of Pittsburgh, 1957 .

Hites, R. W. "A Questionnaire for Measuring Leader-Identification," Amer. Psychol., VIII (1953), 368 (Abstract).

Jambor, H. Discrepanctes in Role Expectations for the Supervisory Pogition. Minneapolis: Univ. of Minnesota, Doctoral Dissertation, 1954. Kahn, R. L. "The Prediction of Productivity," J. soc. Issues,

Katz, D., Maccoby, N., Gurin, G., \& Floor, L. G. Productivity, Supervision and Morale Among Railroad Workers. Ann Arbor, Mich.: Institute for social Research, 1951.

Katz, D., \& Kahn, R. L. "Human Organization and Worker Motivation." In L. Reed Tripp (Ed.), Industrial Productivity. Madison, Wisc.: Industrial Relations Research Association, 1951, 146-171.

Leavitt, H. J. Managerial Psychology. Chicago: Univ. of Chicago Press, 1958.

Likert, R. New Patterns of Management. New York: McGraw-Hi11 Book Co., Inc., 1961 .

Mann, F. C., \& Dent, J. Appraisals of Supervisors and Attitudes of Their Employees in an Electric Power Company. Ann Arbor, Mich.: Institute for Social Research, 1954a. 
Mann, F. C., \& Dent, J. K. "The Supervisor: Member of Two Organizational Families," Hary. bus. Rev., VI (1954b), 103-112.

March, J. G., \& Simon, H. A. Organlzations. New York: John Wiley \& Sons, Inc., 1958.

McGregor, D. The Human Side of Enterprise. New York: McGrawHili Book Co., Inc., 1960 .

Morse, N. Satisfactions in the White-Collar Job. Ann Arbor, Mich.: Institute for social Research, 1953.

Nunnally, J. C. Tests and Measurements. New York: McGrawHili Book Co., Inc., 1959 .

Pelz, D. C. "Influence: A Key to Effective Leadership in the First-Line Supervisor," Personnel, (1952) Nov., 3-11.

Pfiffner, J. Mc. The Supervision of Personnel: Human Relations In the Management of Men. New York: Prentice-Ha11, 1951.

Roethlisberger, F. J. "The Foreman: Master and Victim of Double Talk," Harv. bus. Rev., XXIII (1945), 283-298.

Roff, M. E. "A. Study of Combat Leadership in the Air Force by Means of a Rating Scale: Group Differences," J. Psychol., $\operatorname{XXX}(1950), 229-239$.

Stogdi11, R. M., \& Coons, A. E. Leader Behavior: Its Description and Measurement. Columbus, Ohio: Bureau of Business Research, Ohio State Univ., 1957.

Stouffer, S. A. "An Analysis of Conflicting Social Norms," Amer. sociol. Rev., XIV (1949), 707-717.

Stuhr, A. W. "Some Outcomes of the New York Employer Survey." Social Sclence Research Reports. IV. Surveys and Inventories. Standard Oil Company (New Jersey), 1962.

Tannenbaum, R., Weschler, I. R., Massarick, F. Leadership and Organization: A Behavioral Science Approach. New York: McGraw-Hi11 Book Co., Inc., 1961.

Thurston, L. L. Mitiple-Factor Analysis: A Development and Expansion of the Vectors of the Mind. Chicago: Univ. of Chicago Fress, 1947.

Titus, C. H. The Process of Leadership, Human Relations in the Making. Dubuque: Brown, 1950. 
APPENDICES 


\title{
APPENDIX A
}

\author{
P. A. R.
}

THE PITTSBURGH ADMINISTRATIVE REVIEW

Bernard M. Bass and James A. Vaughan Graduate School of Business University of Pittsburgh

Pittsburgh 13, Pennsylvania 


\section{INTRODUCTION}

This is a survey designed to study how persons actually handle various kinds of administrative situations, how they think they ought to handle them and how they would prefer to handle them.

\section{YOUR DEPARTMENT:}

The words, your department, in the following statements should be interpreted to mean "your immediate subordinates, those persons you directly supervise, those persons who report directly to you, those persons who are one step directly beneath you in your organization's structure."

\section{YOUR ORGANIZATION:}

Your organization refers to "the single, largest, most important division, firm, plant, or institution of which your department is immediately a part." The organization is relatively free of any still larger unit, but it has no subunits within it which are as free.

GENERAL DIRECTIONS:

DO NOT SIGN YOUR NAME TO ANY OF THESE FORMS.

You are asked to indicate on the white answer sheet what you actually do, on the yellow answer sheet what you ought to do, and on the green answer sheet what you prefer to do. Be sure to read the spectfic directions on top of each sheet before proceeding to fill it in. 
MARK ALL ANSWERS ON THE ANSWER SHEETS AS DIRECTED ON THE SHEETS

1. How large is your department?

A. 5 or 1ess B. $6-10$ C. 11-20 D. 21-30

E. Over 30 persons

11. How long have you directed this department?

A. 1 ess than 12 months $B$. 12-23 months C. 2-5 years

D. 6-10 years E. over 10 years

1ii. How large is your organization?

A. under 100 persons B. 100-249 C. 250-499 D. 500-9999

E. 10,000 and up

Iv. How long have you been in your organization?

A. 1 ess than 12 months B. 12-23 months C. 2-5 years

D. 6-10 years E. over 10 years

v. My department subordinates are mainly:

A. sales, clerical (white collar) B. manual, technical (blue collar) C. mixed white and blue $D$. can't say

vi. My department subordinates are mainly:

A. semi-professional B. skilled C. semi-skilled

D. unskilled E. can't say

vii. My department is:

A. Iine or production B. staff or service C. can't say

viii. My organization main1y: (mark more than one if necessary)

A. produces units to customer's orders

B. produces in batches

C. mass produces in assembly lines

D. produces in batch flow processes

E. produces in continuous flow of liquids or solids

1. Before I institute any new plans in my department, I clear them with the boss.

A. always B. often C. occasionally D. seldom E. never

2. Before I take part in an activity within the organization, I find out what the rule book has to say on the

A. always B. fairly often C. occastonally D. once in a while E. very seldom 
3. When a conflict arises among those with whom I work, my concern $\ldots$ is for my immediate subordinates and how they feel about the matter.
A. always B. often C. occasionally D. seldom E. never

4. Coordination and maintenance of departmental activities are issues which I seek the benefit of the thinking and experience of others at my same level in the organization.
A. always
B. often
C. occasionally
D. seldom $\mathrm{E}$. never

5. When involved in matters of concern to the whole organization, I outside the organization.

A. always B. often C. occasionally D. seldom E. never

6. When faced with a decision concerning my participation in an organizational matter, I consult those above my boss or others at his level in the organization.

A. always B. often C. occasionally D. seldom E. never

7. I consider the opinions of persons or agencies outside my organization when making plans or innovations.
A. alway
B. often
C. occasionaily
D. seldom E. never

8. I department. A. always B. often C. occasionally D. seldom E. never

9. Whenever a conflict arises, I pay attention to the position taken by those below me in othe: departments in the organization.
A. always B. often
C. occasionally
D. seldom E. never

10. In recommending members of my department for pay raises, I use the company manual or policy statements as a guide.

A. always B. often C. occasionally D. seldom E. never

11. In coordinating the jobs within my department, I maintain complete independence from my boss.
A. always B. often C. occasionally D. seldom E. never

12. I discount the opinions of my immediate subordinates when I am deciding whether to participate in a given activity in the organization.

A. always B. often C. occasionally D. seldom E. never 
13. When a conflict situation arises in my department, I disregard the feelings of those above my boss or at his level in the organization.

A. always B. often C. occasionally D. seldom E. never

14. In planning any change in the operation of my department, I plave low priority to considering how the change will affect me personally.

A. always B. often C. occasionally D. seldom E. never

15. In reaching decistons concerning how I work with other departments of the organization, I _ _ ignore the rulebooks.

A. always B. often C. occasionally D. seldom E. never

16. In a conflict situation, I my level would handle it.

ignore how others at

A. always B. often C. occasionally D. seldom E. never

17. What I know about persons or groups outside the organization is department.

A. always B. often C. occasionally D. seldom E. never

18. When seeking ways to maintain my departmental program I am indifferent to the attitudes of persons below me In the organization in other departments.

A. always B. often C. occasionally D. seldom E. never

19. Before discussing organization matters with anyone outside out department, I consider what my boss is likely to think about the question.

A. always B. often C. occasionally D. seldom E. never

20. Whether I participate in a particular activity is likely to be determined by what I see other men at my level doing.

A. always B. often C. occasionally D. seldom E. never

21. I consult whatever written guides or rule books are available to help me make judgments concerning the maintenance of my department's program.

A. always B. often C. occasionally D. seldom E. never

22. Most important to me is whether I personally feel that I have done a job wel1, rather than what others think.
A. always
B. often
C. occasionally
D. seldom E. never 
23. I consider the opinions of those above my boss or at his level in the organization in order to maintain my departmental program.
A. always
B. often
C. occasionally
D. seldom E. never

24. My own feelings in a given activity. dictate whether I will participate A. always B. often C. occastonally D. seldom $E$. never

25. It is unimportant whether I personally am satisfied with a decision involving my own and other departments in the organization.

A. always B. often C. occasionally D. seldom E. never

26. The opinions of persons or groups outside the organization are irrelevant in determining whether I particlpate in an activity.

A. always B. often C. occasionally D. seldom E. never

27. I try to see that any conflict in my department or organization is resolved according to who the parties involved are, rather than what the rulebook says.

A. always B. often C. occasionally D. seldom E. never

28. I feel free to recommend changes in pay for those who work under me without consulting my boss.

A. always B. often C. occasionally D. seldom E. never

29. I find it useless to consult with other persons on my same level when planning some innovation in my department.

A. always B. often C. occasionally D. seldom E. never

30. My immediate subordinates have only a minor voice in the coordination of departmental activities.

A. always B. often C. occasionally D. seldom E。 never

31. When making recommendations for salary or other schedules of reward in my department, I consult with persons above my boss or at his level in the organization.

A. always B. often C. occasionally D. seldom E. never

32. I value the thinking of persons below me in the organization in other departments when making plans for innovations in my own department.
A. always
B. often
C. occasionally
D. seldom
E. never 
33. When decisions I make will affect other departments I avold asking persons at my level in those departments for their opinions.
A. always
B. often
C. occasionally
D. seldom E. never

34. My paxticipation in an activity is what my boss thinks about it. Independent of
A. always B. often
C. occasionally
D. seldom
E. never

35. I ignore the suggestions of those above my boss or at his level in the organization, when $I$ am planning some innovation in my department.
A. always
B. often
C. occasionally
D. seldom
E. never

36. I am Indifferent to my immediate subordinates' opinions when I deal with other departments.
A. always B. often
C. occasiona11y
D. seldom
E. never

37. I ignore the situation of persons below me in the organization in other departments when making recommenda.tions for salary or other schedules of reward in my own department.
A. always B. often
C. occasionally
D. seldom
E. never

38. The opinions of persons above my boss or others at his level in the organization are an intra-organizational decision. irrelevant when I am making
A. always
B. often
C. occasionally
D. seldom
E. never

39. When faced with a conflict involving my department, I try to look at it from my boss's point of view.
A. always
B. often
C. occasionally
D. seldom
E. never

40. In establishing salary or other schedules of reward in my department, I their departments.
A. always B. often
C. occasionally
D. seldom E. never

41. In dealing with a conflict in my organization, I consider the effects of possible resolutions on persons or groups outside the organization.
A. always
B. often
C. occasionally
D. seldom
E. never

42. I ask for suggestions or comments from those working directly under me concerning plans or innovations in my department.
A. always
B. often
C. occasionally
D. seldom
E. never 
43. In deciding whether or not to participate in a given activity I discount the opinions of those persons below me in other departments in the organization.
A. always
B. often
C. occastonally
D. seldom
E. never

44. I avoid asking those persons working for me to participate in a periodic review of their salary schedules.
A. always
B. often
C. occasionally
D. seldom E. never

45. In any change which I contemplate for my department, I consider the progress involved in the change as more Important than company rules and regulations.
A. always
B. often
C. occasionally
D. seldom
E. never

46. Persons outside the organization fatl to influence my judgment in any effort to coordinate and maintain the present level of activities in my department.
A. always $B$. often
C. occasional1y
D. seldom
E. never

47. When I am involved in a conflict, I to how the outcome will affect me. am indifferent
A. always
B. often
C. occastonally
D. se1dom
E. never

48. I seek the counsel of persons below me in the organization in other departments when faced with an intraorganizational decision.
A. always
B. often
C. occasionally
D. seldom E. never

49. When I disagree with my boss about how my department should deal with other departments, I usually...
A. keep my real thoughts to myself
B. state my opinion
C. state my opinion and do what the boss says
D. discuss the matter with the boss to reach a mutually acceptable solution
E. pursue the course of action I believe to be right regardless of his opintion

50. When the majority opinion of those persons at my level in the organization is opposed to what I think about how I should participate in the organization, I usually...
A. follow their advice
B. Iisten to them, but do what I thought right originally
C. consult with my boss, then decide
D. re-examine the facts, then decide
E. try to convince them why I'm right and they are wrong 
51. When stated organizational polictes are not flexible or broad enough to permit me sufficient freedom in running my department, I usually...

A. work around them, doing pretty much what I want to do anyhow

B. accept the situation with the hope of eventually changing it

C. Initiate action to remedy the situation

D. withdraw from further concern about the problem

E. start a fight to win quick resolution of my difficulties

52. When my subordinates and I disagree about something within the department, I usually...

A. seek outside advice

B. listen and then hold to my own view

C. make it clear that I have the responsibility and authority for the decision

D. Iisten, evaluate and decide

E. evade the question and direct attention to other matters

53. When I object to outsiders attempting to influence planning and innovation within my department, I usualiy...

A. object to their intrusion

B. Ignore them

C. Iisten and tell them what they might do to help

D. follow their suggestions, if they have authority to make them

E. complatn to my boss or higher authority

54. When revisions in salary structure to increase fairness to all would be of no personal benefit to me, I usually...

A. work for the greatest equity for company and employees

B. make sure the company's position is fully protected

C. find some excuse to satisfy myself

D. do nothing

E. fight for benefits for my employees

55. When my boss and my subordinates disagree seriously, I usually...

A. act as a mediator

B. stay out of the argument and let them fight it out without me getting involved

C. support the position of my boss

D. support the position of my subordinates

E. support whoever I think is right

56. When we disagree about what I should do, my boss most often: 

A. settles the issue by "pulling his rank" on me
B. tries to persuade or convince me as to why he is right and $I$ am wrong
C. provides me an opportunity to share with him the responsibility for developing a mutuliy satisfactory decision
D. lets me do what I please
E. Is completely unpredictable

57. Compared to most departments I have known, I would say that my subordinates are:
A. completely satisfled with their jobs in general
B. moderately satisfled
C. neither satisfied nor dissatisfied
D. moderately dissatisfied
E. completely dissatisfied

58. Compared to most departments I have known, I would say that my current department is:
A. producing at a maximum of demand and capability
B. moderately productive
C. neither high nor low in productivity
D. moderately unproductive
E. producing at a minimum of demand and capability 


\section{ANSWER SHEET}

\section{A DESCRIPTION OF WHAT I ACTUALLY DO}

Directions :

Please indicate your answers to each question or statement by circling the appropriate letter. For example, if your answer to question number is 11-20, then mark your answer below as follows :

i. A B (C) D E

When a question does not apply to you, leave it unmarked. Leave it unmarked also, when you are unsure or don't know the answer.

Fil1 in this description sheet indicating what you actually do, how often you act in the way described by the statements in the $\overline{\text { PAR }}$ booklet.

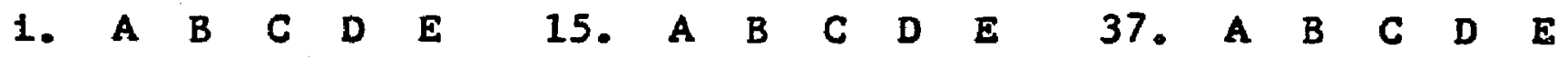

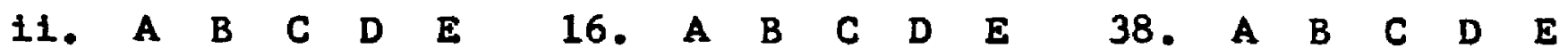

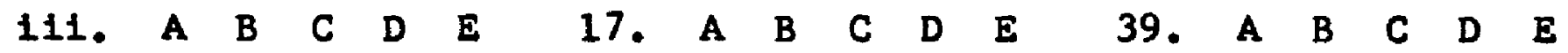

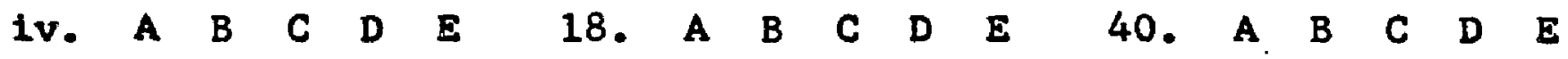

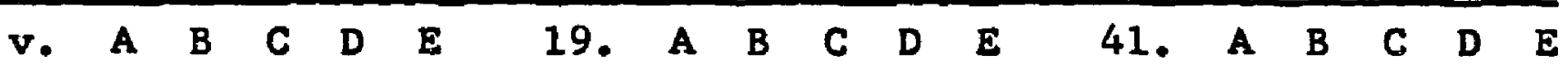

vi. A B vi1. A $\begin{array}{llllllllllllllll} & \text { B } & \text { D } & E & \text { 21. } & \text { A } & \text { B } & \text { C } & \text { D } & E & 43 . & \text { A } & \text { B } & \text { C } & \text { D } & E\end{array}$ vii1. A B C D E $\begin{array}{lllllllllllll} & \text { 22. } & \text { A } & \text { B } & \text { C } & \text { D } & \text { E } & 44 . & \text { A } & \text { B } & \text { C } & \text { D } & \text { E }\end{array}$

1. A $\begin{array}{lllllllllllllllll}\text { B } & C & D & E & 23 . & \text { A } & \text { B } & C & D & E & 45 . & A & B & C & D & E\end{array}$

2. A $\begin{array}{lllllllllllllllll} & \text { B } & C & D & E & 24 . & A & B & C & D & E & 46 . & A & B & C & D & E\end{array}$

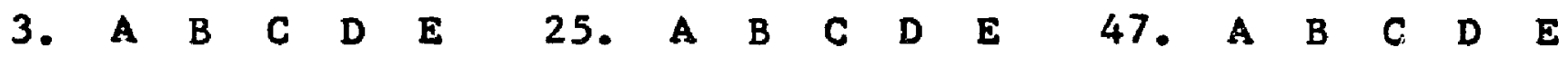

4. \begin{tabular}{llllllllllllllllll} 
A & B & C & D & E & 26. & A & B & C & D & E & 48 & 48 & A & B & C & D & E \\
\hline
\end{tabular}

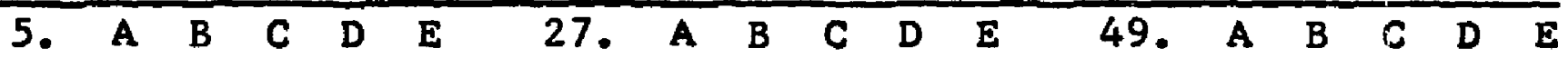

6. A A B

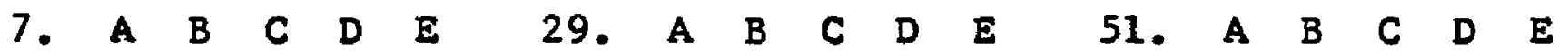

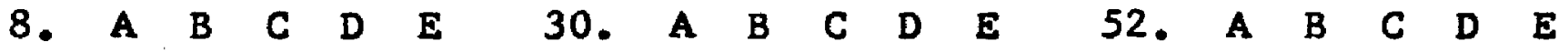

9. A A B

10. A A B

11. A $\begin{array}{llllllllllllllll}\text { B } & C & D & E & 33 . & A & B & C & D & E & 55 . & A & B & C & D & E\end{array}$

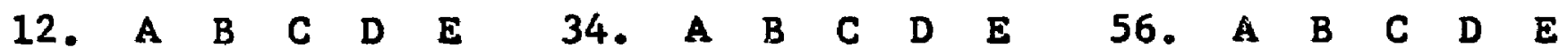

13. A $\begin{array}{lllllllllllllllll} & \text { B } & C & \text { D } & \text { E } & \text { 35. } & \text { A } & \text { B } & \text { C } & \text { D } & \text { E } & 57 . & \text { A } & \text { S } & \text { C } & \text { D } & E\end{array}$
14. A $\begin{array}{llllllllllllllllll}\text { B } & C & D & E & 36 . & \text { A } & \text { B } & \text { C } & \text { D } & \text { E } & 58 . & \text { A } & \text { B } & \text { C } & \text { D } & E\end{array}$ 
APPENDIX B

Intercorrelation Matrix for Items 1 to 48

\begin{tabular}{|c|c|c|c|c|c|c|}
\hline Itein & 1 & 2 & 3 & 4 & 5 & 6 \\
\hline 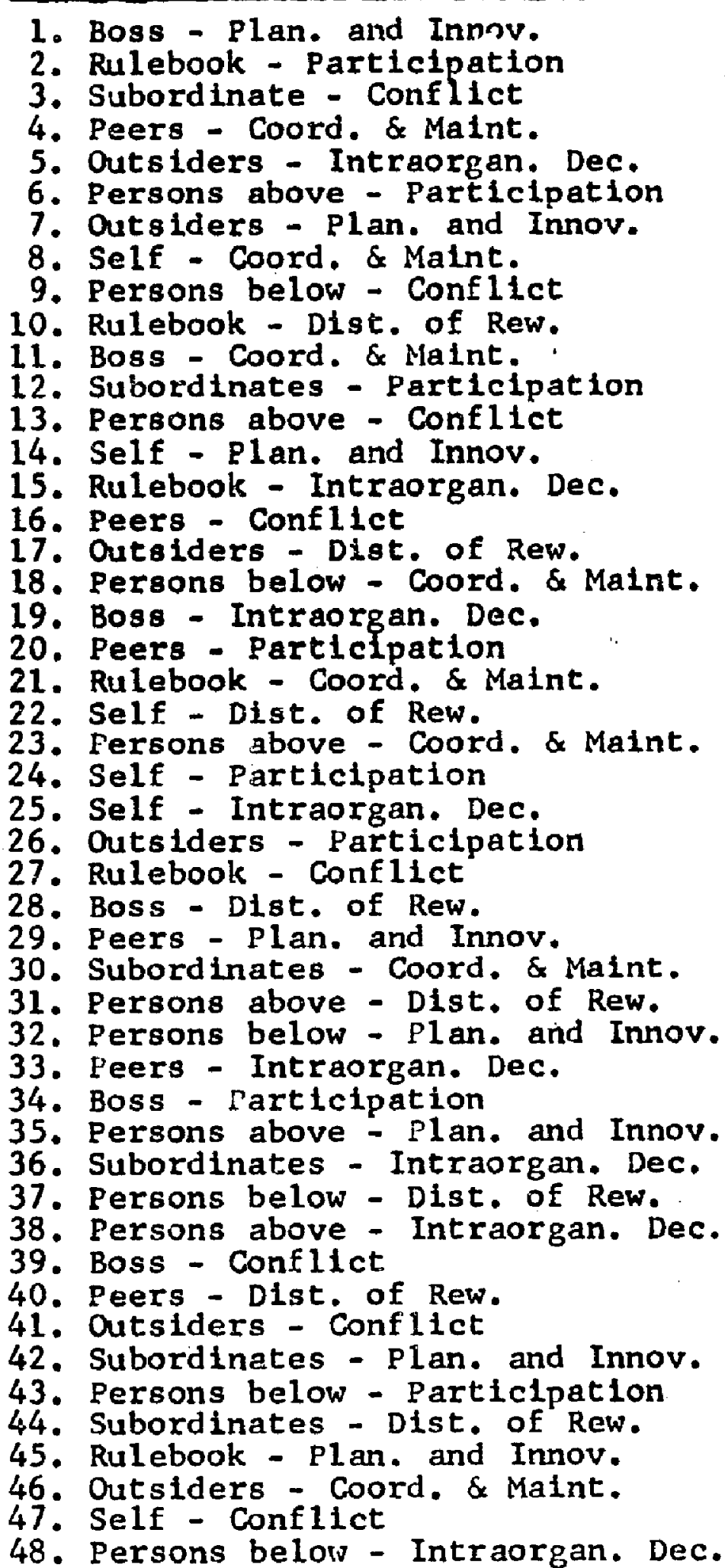 & $\begin{array}{r}39 \\
-04 \\
18 \\
06 \\
00 \\
04 \\
-18 \\
13 \\
02 \\
32 \\
21 \\
25 \\
-07 \\
24 \\
12 \\
02 \\
06 \\
26 \\
-15 \\
06 \\
-06 \\
-13 \\
-20 \\
-13 \\
-08 \\
15 \\
32 \\
09 \\
-09 \\
-04 \\
-05 \\
05 \\
19 \\
-03 \\
06 \\
-05 \\
04 \\
26 \\
-10 \\
08 \\
-05 \\
-02 \\
05 \\
28 \\
-11\end{array}$ & $\begin{array}{r}07 \\
39 \\
06 \\
10 \\
10 \\
-08 \\
13 \\
24 \\
18 \\
30 \\
24 \\
-03 \\
37 \\
25 \\
10 \\
09 \\
36 \\
04 \\
36 \\
01 \\
22 \\
-03 \\
10 \\
-02 \\
38 \\
17 \\
14 \\
-07 \\
-03 \\
09 \\
10 \\
18 \\
04 \\
11 \\
13 \\
15 \\
32 \\
13 \\
18 \\
00 \\
04 \\
-03 \\
13 \\
-17 \\
04\end{array}$ & $\begin{array}{r}-04 \\
07 \\
24 \\
24 \\
285 \\
15 \\
14 \\
08 \\
01 \\
21 \\
05 \\
10 \\
-04 \\
05 \\
08 \\
03 \\
09 \\
08 \\
-04 \\
03 \\
26 \\
07 \\
11 \\
01 \\
-05 \\
04 \\
-16 \\
10 \\
20 \\
03 \\
15 \\
-03 \\
-03 \\
06 \\
02 \\
01 \\
-02 \\
12 \\
01 \\
09 \\
01 \\
00 \\
17 \\
-10 \\
-06 \\
-13 \\
14\end{array}$ & $\begin{array}{r}24 \\
09 \\
18 \\
-05 \\
23 \\
13 \\
16 \\
21 \\
22 \\
02 \\
18 \\
24 \\
06 \\
25 \\
16 \\
13 \\
17 \\
-09 \\
26 \\
00 \\
-11 \\
16 \\
13 \\
06 \\
39 \\
03 \\
15 \\
34 \\
13 \\
15 \\
-03 \\
00 \\
16 \\
10 \\
33 \\
04 \\
19 \\
35 \\
-04 \\
15 \\
00 \\
-09 \\
-01 \\
02\end{array}$ & $\begin{array}{r}03 \\
12 \\
04 \\
11 \\
15 \\
00 \\
14 \\
21 \\
-08 \\
-05 \\
01 \\
21 \\
07 \\
04 \\
12 \\
-07 \\
-18 \\
16 \\
-12 \\
-03 \\
08 \\
17 \\
-06 \\
08 \\
07 \\
09 \\
09 \\
14 \\
08 \\
04 \\
00 \\
13 \\
08 \\
29 \\
10 \\
16 \\
22 \\
02 \\
24 \\
02 \\
-02 \\
-05 \\
01\end{array}$ & $\begin{array}{r}17 \\
28 \\
04 \\
01 \\
-10 \\
-06 \\
-10 \\
-06 \\
-12 \\
20 \\
03 \\
10 \\
-01 \\
19 \\
08 \\
07 \\
14 \\
02 \\
09 \\
-11 \\
10 \\
01 \\
13 \\
16 \\
32 \\
08 \\
-15 \\
-08 \\
00 \\
13 \\
07 \\
17 \\
-02 \\
10 \\
-15 \\
-03 \\
-03\end{array}$ \\
\hline
\end{tabular}


Intercorrelation Matrix for Items 1 to 48 (cont.)

\begin{tabular}{|c|c|c|c|c|c|c|c|c|c|c|c|c|c|c|}
\hline & 7 & 8 & 9 & 10 & 11 & 12 & 3 & 14 & & 16 & 17 & & & 20 \\
\hline & 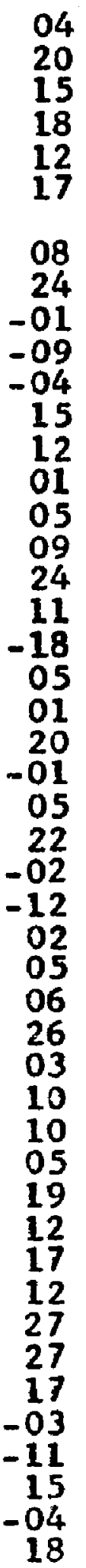 & $\begin{array}{r}-18 \\
-08 \\
14 \\
-05 \\
04 \\
28 \\
08 \\
-04 \\
19 \\
-20 \\
-03 \\
-06 \\
-14 \\
-16 \\
24 \\
-04 \\
02 \\
07 \\
02 \\
03 \\
-02 \\
18 \\
16 \\
02 \\
04 \\
-09 \\
-07 \\
04 \\
-11 \\
-14 \\
-131 \\
-01 \\
-12 \\
-12 \\
-121 \\
11 \\
09 \\
09 \\
-04 \\
-16 \\
-13 \\
-03 \\
-10\end{array}$ & $\begin{array}{r}13 \\
13 \\
08 \\
23 \\
11 \\
04 \\
24 \\
-04 \\
-02 \\
-07 \\
22 \\
13 \\
02 \\
23 \\
01 \\
18 \\
33 \\
-12 \\
10 \\
-08 \\
-15 \\
02 \\
-04 \\
02 \\
14 \\
-03 \\
-15 \\
07 \\
17 \\
00 \\
22 \\
-16 \\
03 \\
-02 \\
06 \\
08 \\
27 \\
07 \\
08 \\
00 \\
14 \\
24 \\
07 \\
02 \\
04 \\
-02\end{array}$ & 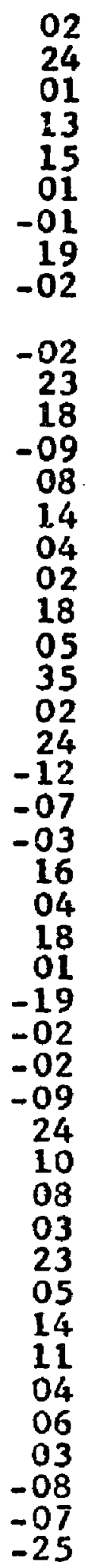 & 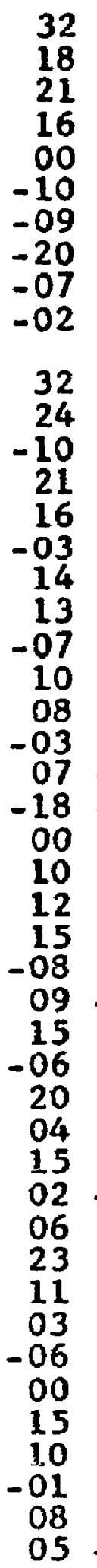 & $\begin{array}{r}21 \\
30 \\
05 \\
21 \\
14 \\
-06 \\
-04 \\
-03 \\
22 \\
23 \\
32 \\
30 \\
-09 \\
32 \\
16 \\
16 \\
20 \\
06 \\
03 \\
18 \\
01 \\
15 \\
-07 \\
-04 \\
15 \\
26 \\
04 \\
23 \\
23 \\
-15 \\
12 \\
15 \\
17 \\
19 \\
30 \\
-03 \\
23 \\
21 \\
03 \\
06 \\
14 \\
12 \\
04 \\
11 \\
01 \\
-08\end{array}$ & $\begin{array}{r}25 \\
24 \\
10 \\
22 \\
21 \\
-10 \\
15 \\
-06 \\
13 \\
18 \\
24 \\
30 \\
-03 \\
24 \\
07 \\
01 \\
13 \\
22 \\
-23 \\
22 \\
-08 \\
20 \\
-17 \\
-11 \\
11 \\
20 \\
09 \\
11 \\
-04 \\
-05 \\
11 \\
14 \\
20 \\
28 \\
04 \\
00 \\
15 \\
42 \\
09 \\
13 \\
14 \\
19 \\
11 \\
-08 \\
-13\end{array}$ & $\begin{array}{r}-0 \\
-0 \\
0 \\
-0 \\
-0 \\
1 \\
-1 \\
0 \\
-0 \\
-1 \\
-0 \\
-0 \\
0 \\
0 \\
0 \\
-0 \\
-1 \\
0 \\
0 \\
1 \\
0 \\
-2 \\
1 \\
0 \\
0 \\
-1 \\
-0 \\
0 \\
-1 \\
1 \\
0 \\
-1 \\
-0 \\
-0 \\
-2 \\
-0 \\
-1 \\
-0 \\
-0 \\
-0 \\
-0 \\
0 \\
0 \\
-0 \\
20 \\
2 \\
0 \\
0\end{array}$ & $\begin{array}{r}24 \\
37 \\
05 \\
18 \\
-05 \\
-12 \\
01 \\
-16 \\
23 \\
08 \\
21 \\
32 \\
24 \\
05 \\
21 \\
-06 \\
28 \\
09 \\
-10 \\
25 \\
-05 \\
-06 \\
-09 \\
13 \\
04 \\
22 \\
13 \\
18 \\
-03 \\
-08 \\
16 \\
02 \\
20 \\
17 \\
14 \\
00 \\
16 \\
08 \\
03 \\
09 \\
-05 \\
19 \\
13 \\
04 \\
-01\end{array}$ & $\begin{array}{r}12 \\
25 \\
08 \\
24 \\
01 \\
20 \\
05 \\
24 \\
01 \\
14 \\
16 \\
16 \\
07 \\
02 \\
21 \\
09 \\
09 \\
20 \\
14 \\
22 \\
17 \\
09 \\
20 \\
00 \\
10 \\
06 \\
06 \\
17 \\
35 \\
03 \\
12 \\
11 \\
06 \\
21 \\
06 \\
20 \\
27 \\
24 \\
24 \\
09 \\
-08 \\
-08 \\
08 \\
07 \\
05 \\
03 \\
07\end{array}$ & $\begin{array}{r}02 \\
10 \\
03 \\
06 \\
21 \\
03 \\
09 \\
-04 \\
18 \\
04 \\
-03 \\
16 \\
01 \\
-01 \\
-06 \\
09 \\
12 \\
02 \\
04 \\
-07 \\
-15 \\
04 \\
-10 \\
00 \\
26 \\
09 \\
02 \\
-02 \\
01 \\
10 \\
-01 \\
01 \\
19 \\
02 \\
-03 \\
42 \\
00 \\
12 \\
08 \\
08 \\
09 \\
05 \\
08 \\
11 \\
12 \\
03\end{array}$ & 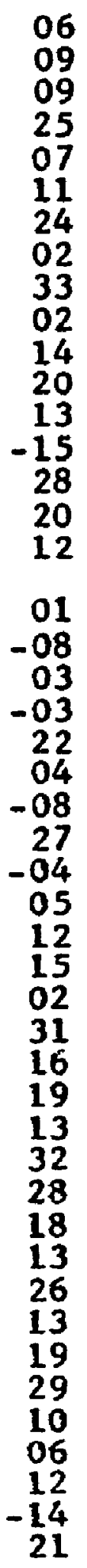 & 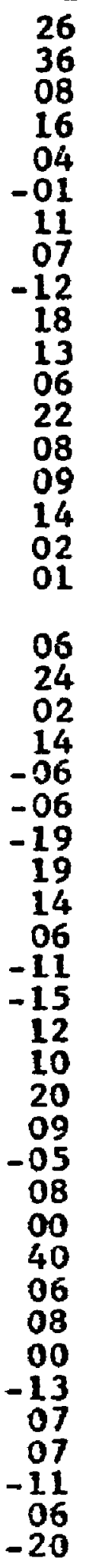 & $\begin{array}{r}-0 \\
-0 \\
-2 \\
0 \\
2 \\
1 \\
1 \\
2 \\
-1 \\
-0\end{array}$ \\
\hline
\end{tabular}


Intercorrelation Matrix for Items 1 to 48 (comt.)

\begin{tabular}{|c|c|c|c|c|c|c|c|c|c|c|c|c|c|c|}
\hline & & & 23 & & & 26 & & 28 & & & & 32 & & 3 \\
\hline $\begin{array}{l}6 \\
7 \\
8\end{array}$ & $\begin{array}{r}06 \\
36 \\
03 \\
17 \\
-07 \\
08 \\
05 \\
03 \\
-08 \\
35 \\
10 \\
18 \\
22 \\
13 \\
25 \\
17 \\
-07 \\
03 \\
24 \\
04 \\
\\
22 \\
21 \\
00 \\
-07 \\
00 \\
17 \\
-08 \\
34 \\
19 \\
02 \\
22 \\
-07 \\
09 \\
29 \\
07 \\
-10 \\
07 \\
17 \\
11 \\
00 \\
02 \\
-14 \\
-11 \\
08\end{array}$ & $\begin{array}{r}05 \\
09 \\
22 \\
-01 \\
17 \\
03 \\
06 \\
11 \\
05 \\
-02 \\
-11 \\
-15 \\
-07 \\
06 \\
-06 \\
02 \\
-01 \\
-11 \\
11 \\
-19 \\
09 \\
-08 \\
-12 \\
-15 \\
03\end{array}$ & $\begin{array}{r}-13 \\
22 \\
07 \\
26 \\
16 \\
14 \\
20 \\
18 \\
02 \\
24 \\
-03 \\
15 \\
20 \\
-21 \\
-07 \\
20 \\
04 \\
22 \\
14 \\
09 \\
21 \\
05\end{array}$ & $\begin{array}{r}05 \\
-06 \\
-10 \\
-10 \\
06 \\
-04 \\
07 \\
-01 \\
-09 \\
-17 \\
-10 \\
-04 \\
-03 \\
-13 \\
-07 \\
04 \\
04 \\
03 \\
03 \\
-03 \\
-04 \\
-04 \\
08 \\
09\end{array}$ & $\begin{array}{r}-13 \\
10 \\
01 \\
-11 \\
-03 \\
09 \\
05 \\
02 \\
02 \\
-07 \\
-18 \\
-04 \\
-11 \\
06 \\
13 \\
10 \\
00 \\
-08 \\
-06 \\
-07 \\
-07 \\
22 \\
02 \\
05\end{array}$ & $\begin{array}{r}-08 \\
-02 \\
-05 \\
16 \\
08 \\
-11 \\
22 \\
04 \\
14 \\
-03 \\
00 \\
15 \\
11 \\
05 \\
04 \\
06 \\
26 \\
27 \\
-19 \\
-09 \\
00 \\
-01 \\
21 \\
-06 \\
05\end{array}$ & $\begin{array}{r}15 \\
38 \\
04 \\
13 \\
17 \\
10 \\
-02 \\
-09 \\
-03 \\
16 \\
10 \\
26 \\
20 \\
-13 \\
22 \\
06 \\
09 \\
-04 \\
19 \\
-15 \\
17 \\
17 \\
19 \\
-10 \\
15 \\
-11\end{array}$ & $\begin{array}{r}32 \\
17 \\
-16 \\
06 \\
-06 \\
01 \\
-12 \\
-07 \\
-15 \\
04 \\
12 \\
04 \\
09 \\
-05 \\
13 \\
17 \\
02 \\
05 \\
14 \\
-19 \\
-08 \\
03 \\
-08 \\
-10 \\
04 \\
-06 \\
11\end{array}$ & $\begin{array}{r}09 \\
14 \\
10 \\
39 \\
08 \\
13 \\
02 \\
04 \\
07 \\
18 \\
05 \\
23 \\
11 \\
06 \\
18 \\
35 \\
-02 \\
12 \\
06 \\
04 \\
34 \\
06 \\
16 \\
06 \\
-02 \\
17 \\
15 \\
16 \\
-19 \\
01 \\
01 \\
37 \\
15 \\
03 \\
13 \\
-01 \\
03 \\
32 \\
00 \\
08 \\
00 \\
22 \\
10 \\
22 \\
00\end{array}$ & $\begin{array}{r}2 \\
0 \\
0 \\
1 \\
0 \\
1 \\
1 \\
0 \\
-0 \\
2 \\
-0 \\
-1 \\
-0 \\
0 \\
0 \\
1 \\
-1 \\
1 \\
1 \\
1 \\
2 \\
-0 \\
0 \\
2 \\
0 \\
-2 \\
1\end{array}$ & $\begin{array}{r}0 \\
1 \\
0 \\
3 \\
0 \\
1 \\
0 \\
-1 \\
0 \\
-1 \\
-0 \\
1 \\
-0 \\
1 \\
1 \\
0 \\
-1 \\
0 \\
0 \\
0 \\
0 \\
0 \\
-0 \\
1 \\
-0 \\
1 \\
0 \\
-0\end{array}$ & 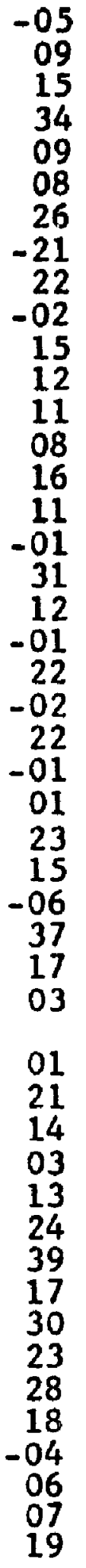 & $\begin{array}{r}-00 \\
15 \\
14 \\
-13 \\
02 \\
06 \\
01 \\
16 \\
10 \\
-06 \\
-07 \\
-11 \\
19 \\
-09 \\
11 \\
10 \\
02 \\
10 \\
15 \\
-03 \\
-10 \\
01 \\
27 \\
10 \\
22 \\
11 \\
06 \\
14 \\
-06 \\
13 \\
13 \\
20 \\
013 \\
-09\end{array}$ & $\begin{array}{r}1 \\
1 \\
-0 \\
1 \\
0 \\
-0 \\
1 \\
-1 \\
0 \\
-0 \\
2 \\
1 \\
2 \\
-0\end{array}$ \\
\hline
\end{tabular}


Intercorrelation Matrix for Items 1 to 48 (cont.)

\begin{tabular}{|c|c|c|c|c|c|c|c|c|c|c|c|c|c|c|}
\hline & 35 & 36 & & 38 & 39 & 40 & & 42 & 43 & 44 & 45 & 46 & 47 & 48 \\
\hline $\begin{array}{l}1 \\
2 \\
3 \\
4 \\
5 \\
6 \\
7 \\
8 \\
9 \\
0\end{array}$ & $\begin{array}{r}-03 \\
04 \\
06 \\
-03 \\
04 \\
00 \\
10 \\
21 \\
-02 \\
24 \\
04 \\
19 \\
28 \\
-03 \\
17 \\
06 \\
02 \\
13 \\
09 \\
-20 \\
29 \\
-07 \\
33 \\
-10 \\
-11 \\
16 \\
12 \\
06 \\
13 \\
13 \\
01 \\
14 \\
10 \\
31 \\
-03\end{array}$ & $\begin{array}{r}06 \\
11 \\
02 \\
00 \\
00 \\
13 \\
05 \\
11 \\
05 \\
10 \\
15 \\
30 \\
04 \\
-25 \\
14 \\
20 \\
-03 \\
32 \\
-05 \\
02 \\
07 \\
06 \\
06 \\
-04 \\
-02 \\
05 \\
11 \\
-06 \\
-01 \\
34 \\
-13 \\
03 \\
22 \\
16 \\
14 \\
-04\end{array}$ & $\begin{array}{r}-05 \\
13 \\
01 \\
16 \\
13 \\
07 \\
19 \\
09 \\
08 \\
08 \\
02 \\
-03 \\
00 \\
-04 \\
00 \\
27 \\
42 \\
28 \\
08 \\
21 \\
-10 \\
-06 \\
27 \\
-03 \\
06 \\
27 \\
-01 \\
06 \\
-03 \\
-12 \\
10 \\
13 \\
11 \\
20 \\
14 \\
10\end{array}$ & $\begin{array}{r}04 \\
15 \\
-02 \\
10 \\
08 \\
17 \\
12 \\
09 \\
27 \\
03 \\
06 \\
23 \\
15 \\
-17 \\
16 \\
24 \\
00 \\
18 \\
00 \\
15 \\
07 \\
02 \\
31 \\
-13 \\
11 \\
15 \\
01 \\
-05 \\
03 \\
27 \\
13 \\
24 \\
06 \\
26 \\
23 \\
28 \\
13\end{array}$ & $\begin{array}{r}26 \\
32 \\
12 \\
33 \\
29 \\
-02 \\
17 \\
-04 \\
07 \\
23 \\
23 \\
21 \\
42 \\
-07 \\
08 \\
24 \\
12 \\
13 \\
40 \\
14 \\
17 \\
-01 \\
28 \\
-07 \\
-11 \\
18 \\
08 \\
04 \\
32 \\
-03 \\
00 \\
39 \\
14 \\
24 \\
11 \\
06 \\
23 \\
17 \\
-0\end{array}$ & $\begin{array}{r}-10 \\
13 \\
01 \\
04 \\
10 \\
10 \\
12 \\
16 \\
08 \\
05 \\
11 \\
03 \\
09 \\
-03 \\
03 \\
09 \\
08 \\
26 \\
06 \\
23 \\
00 \\
-11 \\
21 \\
04 \\
00 \\
05 \\
-09 \\
00 \\
-09 \\
-10 \\
21 \\
17 \\
03 \\
26 \\
15 \\
-01 \\
44 \\
34 \\
18\end{array}$ & $\begin{array}{r}08 \\
18 \\
09 \\
19 \\
16 \\
-15 \\
27 \\
-12 \\
00 \\
14 \\
03 \\
06 \\
13 \\
-07 \\
09 \\
-08 \\
08 \\
13 \\
08 \\
-11 \\
14 \\
11 \\
14 \\
04 \\
02 \\
22 \\
-06 \\
-10 \\
00 \\
-04 \\
01 \\
30 \\
13 \\
25 \\
13 \\
07 \\
17 \\
16 \\
40 \\
23\end{array}$ & $\begin{array}{r}-05 \\
00 \\
01 \\
35 \\
22 \\
-03 \\
27 \\
-03 \\
14 \\
11 \\
-06 \\
14 \\
15 \\
-06 \\
-05 \\
-08 \\
09 \\
19 \\
00 \\
-03 \\
-14 \\
-19 \\
21 \\
03 \\
07 \\
16 \\
06 \\
-12 \\
03 \\
10 \\
-11 \\
23 \\
20 \\
14 \\
04 \\
09 \\
19 \\
15 \\
13 \\
04 \\
17\end{array}$ & $\begin{array}{r}-02 \\
04 \\
00 \\
-04 \\
02 \\
16 \\
17 \\
-18 \\
24 \\
04 \\
00 \\
12 \\
19 \\
07 \\
19 \\
08 \\
05 \\
29 \\
-13 \\
00 \\
11 \\
09 \\
13 \\
03 \\
13 \\
20 \\
-03 \\
-08 \\
00 \\
21 \\
-02 \\
28 \\
-06 \\
03 \\
02 \\
12 \\
16 \\
30 \\
12 \\
26 \\
18 \\
04\end{array}$ & 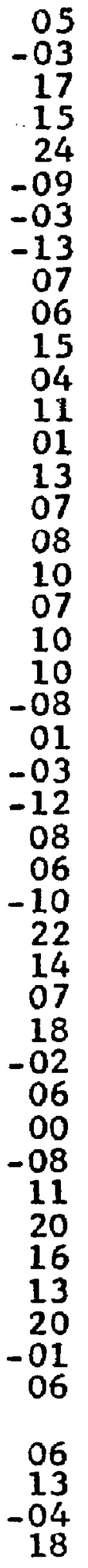 & $\begin{array}{r}28 \\
13 \\
-10 \\
00 \\
02 \\
-16 \\
-11 \\
-01 \\
02 \\
03 \\
10 \\
11 \\
12 \\
-06 \\
18 \\
05 \\
11 \\
06 \\
07 \\
01 \\
08 \\
-12 \\
-08 \\
-04 \\
-26 \\
-06 \\
16 \\
22 \\
10 \\
-05 \\
00 \\
-04 \\
13 \\
05 \\
15 \\
-04 \\
02 \\
-07 \\
04 \\
-02 \\
-04 \\
-09 \\
-18 \\
06 \\
\\
04\end{array}$ & $\begin{array}{r}-11 \\
-17 \\
-06 \\
-09 \\
-02 \\
-01 \\
15 \\
01 \\
04 \\
-08 \\
-01 \\
01 \\
-08 \\
20 \\
04 \\
03 \\
12 \\
12 \\
-11 \\
15 \\
02 \\
-15 \\
03 \\
-04 \\
-14 \\
27 \\
-33 \\
-04 \\
00 \\
10 \\
24 \\
06 \\
01 \\
20 \\
18 \\
-02 \\
27 \\
15 \\
01 \\
24 \\
08 \\
-06 \\
29 \\
13 \\
-01\end{array}$ & $\begin{array}{r}09 \\
04 \\
-13 \\
01 \\
-05 \\
-10 \\
-04 \\
-10 \\
-02 \\
-07 \\
08 \\
25 \\
13 \\
24 \\
00 \\
-07 \\
-07 \\
-14 \\
06 \\
10 \\
28 \\
03 \\
03 \\
08 \\
08 \\
13 \\
-04 \\
-09 \\
22 \\
06 \\
03 \\
07 \\
13 \\
19 \\
17 \\
00 \\
-14 \\
-09 \\
08 \\
-04 \\
04 \\
07 \\
01 \\
-04 \\
14 \\
04 \\
01\end{array}$ & $\begin{array}{r}1 \\
0 \\
-2 \\
0 \\
-0 \\
-1 \\
0 \\
-1 \\
-0 \\
0 \\
2 \\
-2 \\
1 \\
-1 \\
0 \\
0 \\
0 \\
-0 \\
1 \\
-2 \\
-1 \\
0 \\
1 \\
2 \\
1 \\
0 \\
0 \\
-0 \\
0 \\
2 \\
1 \\
0 \\
2 \\
1 \\
0 \\
1 \\
1 \\
-1 \\
2 \\
0\end{array}$ \\
\hline
\end{tabular}




\section{APPENDIX $C$}

Partial Summary of Analyses of Variance of Factor and Subscale Scores

\begin{tabular}{|c|c|c|c|c|c|c|}
\hline$\frac{\text { Item }}{11}$ & $\frac{\text { Factor }}{I} \begin{array}{c}I V \\
V\end{array}$ & Subscale & $\begin{array}{l}\frac{\text { df }}{101} \\
3 / 101 \\
3 / 101 \\
3 / 101 \\
3 / 101 \\
3 / 101\end{array}$ & $\begin{array}{c}\text { MS } \\
22.49 / 8.78 \\
5.86 / 5.13 \\
12.88 / 7.88 \\
15.87 / 9.51 \\
12.01 / 14.52\end{array}$ & $\begin{array}{l}\frac{F}{F} \\
2.561 \\
1.142 \\
1.636 \\
1.668 \\
.827\end{array}$ & p \\
\hline iv & $\underset{\mathbf{I V}}{\operatorname{III}}$ & $\begin{array}{r}2 \\
5 \\
6 \\
12 \\
13\end{array}$ & $\begin{array}{l}4 / 103 \\
4 / 103 \\
4 / 103 \\
4 / 103 \\
4 / 103 \\
4 / 103 \\
4 / 103 \\
4 / 103\end{array}$ & $\begin{array}{r}7.71 / 3.63 \\
9.05 / 4.86 \\
1.99 / 8.08 \\
25.86 / 10.27 \\
5.51 / 9.60 \\
17.53 / 13.77 \\
10.55 / 8.16 \\
14.39 / 9.03\end{array}$ & $\begin{array}{r}2.124 \\
1.862 \\
.246 \\
2.519 \\
.574 \\
1.272 \\
1.292 \\
1.594\end{array}$ & .05 \\
\hline$v$ & $I \frac{I}{V}$ & $\begin{array}{r}1 \\
2 \\
3 \\
4 \\
6 \\
7 \\
9 \\
10 \\
14\end{array}$ & $\begin{array}{l}2 / 77 \\
2 / 77 \\
2 / 77 \\
2 / 77 \\
2 / 77 \\
2 / 77 \\
2 / 77 \\
2 / 77 \\
2 / 77 \\
2 / 77 \\
2 / 77 \\
2 / 77\end{array}$ & $\begin{array}{l}42.90 / 8.08 \\
51.37 / 9.91 \\
30.27 / 7.07 \\
42.41 / 7.07 \\
19.84 / 9.79 \\
32.41 / 10.53 \\
27.37 / / 1 \% .30 \\
30.20 / / 1.78 \\
51.83 / 11.42 \\
33.00 / 6.41 \\
73.42 / 11.24 \\
40.36 / 12.20\end{array}$ & $\begin{array}{l}5.311 \\
5.186 \\
4.295 \\
6.004 \\
2.026 \\
3.077 \\
2.226 \\
2.564 \\
4.537 \\
5.150 \\
6.529 \\
3.308\end{array}$ & $\begin{array}{l}.01 \\
.01 \\
.05 \\
.01 \\
.05\end{array}$ \\
\hline vi & II & $\begin{array}{r}3 \\
7 \\
10 \\
14\end{array}$ & $\begin{array}{l}3 / 83 \\
3 / 83 \\
3 / 83 \\
3 / 83 \\
3 / 83 \\
3 / 83\end{array}$ & $\begin{array}{l}19.08 / 8.92 \\
41.97 / 10.93 \\
20.33 / 10.11 \\
30.10 / 12.26 \\
56.51 / 11.04 \\
27.34 / 11.80\end{array}$ & $\begin{array}{l}2.139 \\
3.840 \\
2.012 \\
2.456 \\
5.118 \\
2.316\end{array}$ & .05 \\
\hline
\end{tabular}


Partial Summary of Analyses of Variance of Factor and Subscale Scores (cont.)

\begin{tabular}{|c|c|c|c|c|c|}
\hline Item & Factor & Subscale & df & MS & $\underline{F}$ \\
\hline 49 & II & $\begin{array}{r}2 \\
3 \\
4 \\
5 \\
6 \\
7 \\
8 \\
9 \\
10 \\
13 \\
14\end{array}$ & $\begin{array}{l}2 / 106 \\
2 / 106 \\
2 / 106 \\
2 / 106 \\
2 / 106 \\
2 / 106 \\
2 / 106 \\
2 / 106 \\
2 / 106 \\
2 / 106 \\
2 / 106 \\
2 / 106\end{array}$ & $\begin{array}{r}28.78 / 11.05 \\
23.15 / 10.52 \\
23.80 / 10.17 \\
10.23 / 11.79 \\
27.39 / 9.92 \\
33.13 / 13.45 \\
17.65 / 12.10 \\
25.99 / 8.17 \\
10.16 / 7.14 \\
57.87 / 12.31 \\
9.79 / 9.19 \\
7.72 / 12.50\end{array}$ & $\begin{array}{r}2.604 \\
2.200 \\
2.341 \\
.868 \\
2.762 \\
2.462 \\
1.459 \\
3.181 \\
1.424 \\
4.699 \\
1.066 \\
.617\end{array}$ \\
\hline 50 & & $\begin{array}{r}1 \\
2 \\
3 \\
7 \\
8 \\
13\end{array}$ & $\begin{array}{l}3 / 98 \\
3 / 98 \\
3 / 98 \\
3 / 98 \\
3 / 98 \\
3 / 98\end{array}$ & $\begin{array}{l}16.97 / 8.43 \\
17.61 / 10.50 \\
29.19 / 8.97 \\
32.85 / 10.32 \\
20.40 / 7.81 \\
26.88 / 9.12\end{array}$ & $\begin{array}{l}2.035 \\
1.677 \\
3.253 \\
3.185 \\
2.612 \\
2.949\end{array}$ \\
\hline 51 & $\begin{array}{l}I \frac{I}{I} \\
I V \\
V\end{array}$ & $\begin{array}{r}1 \\
2 \\
3 \\
4 \\
8 \\
9 \\
10 \\
13 \\
14\end{array}$ & $\begin{array}{l}2 / 91 \\
2 / 91 \\
2 / 91 \\
2 / 91 \\
2 / 91 \\
2 / 91 \\
2 / 91 \\
2 / 91 \\
2 / 91 \\
2 / 91 \\
2 / 91 \\
2 / 91 \\
2 / 91\end{array}$ & $\begin{array}{l}47.61 / 8.43 \\
28.10 / 10.73 \\
14.99 / 4.37 \\
22.34 / 8.20 \\
54.87 / 6.51 \\
50.86 / 10.10 \\
88.43 / 9.33 \\
38.33 / 10.63 \\
35.04 / 7.99 \\
30.27 / 6.70 \\
66.04 / 12.50 \\
29.09 / 7.75 \\
41.36 / 12.28\end{array}$ & $\begin{array}{l}5.649 \\
2.619 \\
3.430 \\
2.726 \\
8.425 \\
5.036 \\
9.480 \\
3.606 \\
4.383 \\
4.520 \\
5.285 \\
3.755 \\
3.369\end{array}$ \\
\hline 53 & & $\begin{array}{r}2 \\
4 \\
11 \\
13\end{array}$ & $\begin{array}{l}2 / 96 \\
2 / 96 \\
2 / 96 \\
2 / 96\end{array}$ & $\begin{array}{r}22.21 / 10.58 \\
12.76 / 12.21 \\
5.70 / 10.01 \\
34.79 / 8.83\end{array}$ & $\begin{array}{r}2.221 \\
1.276 \\
.570 \\
3.940\end{array}$ \\
\hline
\end{tabular}


Partial Summary of Analyges of Variance of Factor and Subscale Scores (cont.)

\begin{tabular}{|c|c|c|c|c|c|}
\hline Item & Factor & Subscale & df & MS & $\underline{F}$ \\
\hline 55 & III & 8 & $\begin{array}{l}3 / 91 \\
3 / 91 \\
3 / 91\end{array}$ & $\begin{array}{l}17.30 / 3.49 \\
10.10 / 5.10 \\
23.57 / 8.00\end{array}$ & $\begin{array}{l}4.958 \\
1.980 \\
2.947\end{array}$ \\
\hline 56 & II & $\begin{array}{l}1 \\
4 \\
7 \\
8\end{array}$ & $\begin{array}{l}3 / 99 \\
3 / 99 \\
3 / 99 \\
3 / 99 \\
3 / 99 \\
3 / 99 \\
3 / 99\end{array}$ & $\begin{array}{r}9.25 / 9.17 \\
12.65 / 11.16 \\
18.85 / 7.46 \\
23.64 / 7.72 \\
22.06 / 11.90 \\
24.64 / 11.50 \\
35.72 / 7.41\end{array}$ & $\begin{array}{l}1.009 \\
1.133 \\
2.527 \\
3.062 \\
1.854 \\
2.143 \\
4.820\end{array}$ \\
\hline 57 & V & $\begin{array}{r}4 \\
5 \\
7 \\
10 \\
13\end{array}$ & $\begin{array}{l}3 / 97 \\
3 / 97 \\
3 / 97 \\
3 / 97 \\
3 / 97 \\
3 / 97\end{array}$ & $\begin{array}{r}5.20 / 7.94 \\
22.36 / 11.91 \\
58.26 / 8.11 \\
18.09 / 12.03 \\
40.18 / 12.64 \\
20.47 / 9.16\end{array}$ & $\begin{array}{l}.655 \\
1.878 \\
7.186 \\
1.504 \\
3.178 \\
2.235\end{array}$ \\
\hline
\end{tabular}

Levels

II

$2 / 104$

$2 / 104$

$2 / 104$

$2 / 104$
$112.94 / 9.56$

$24.40 / 13.38$ $103.72 / 10.54$ $12.58 / 13.35$
11.810

1.824

9.841

.943
.01 .01

Departments

$$
\text { II }
$$

$4 / 97$
$4 / 97$

$4 / 97$

$4 / 97$

$4 / 97$

$4 / 97$

$4 / 97$

$4 / 97$

10

$4 / 97$

$4 / 97$

.05

.01

.05

.05

.05

.01
2.404

3.065

2.481

3.435

2.738

2.336

4.090

.949

1.252 


\section{VITA}

James Agnew Vaughan, Jr. was born in Shannon, Mississippi, on February 21, 1936. He was graduated from Amory High School in Amory, Mississippi, in 1954. He received a Bachelor of Arts degree in philosophy from Millsaps College in Jackson, Mississippi, in 1958 and a Master of Arts degree in psychology from Wesleyan University in Middletown, Connecticut, in 1960. In the same year he enrolled in the graduate school at Louisiana State University. 


\section{GXAMINATION AND THESIS RHPORT}

Candidate: James Agnew Vaugtan, Jr.

Major Field: Psychology

Title of Thesis: Surveying the Man-in-the-Middle of an Industrial Organization

Approved:

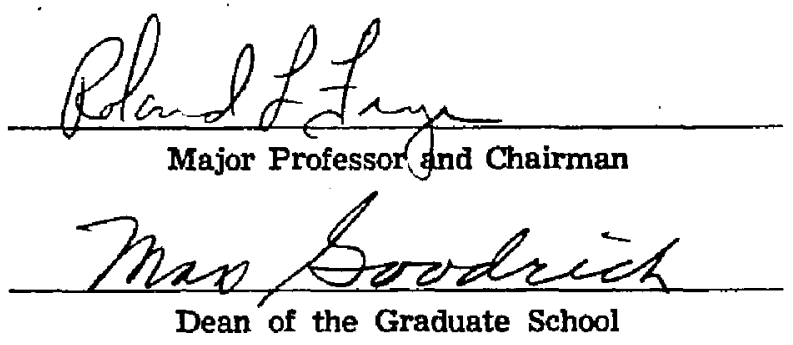

EXAMINING COMMITTEE:
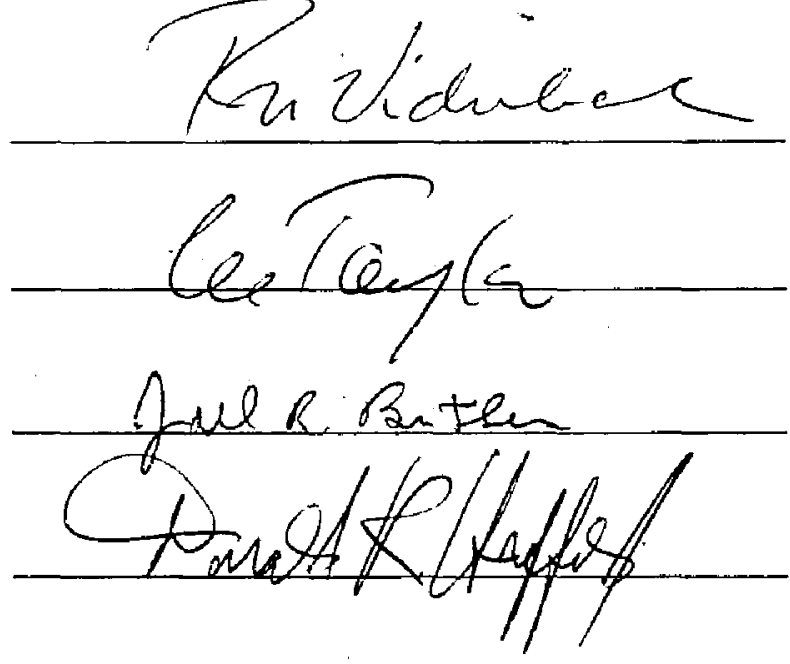

Date of Examination:

July 29,1963 